\title{
A Facile Synthesis of the Basic Steroidal Skeleton Using a Pauson-Khand Reaction as a Key Step
}

\author{
Do Han Kim, Kwang Kim, and Young Keun Chung* \\ Intelligent Textile System Research Center, and Department of Chemistry, \\ College of Natural Sciences, Seoul National University, Seoul 151-747, Korea
}

ykchung@snu.ac.kr

Supporting Information

Table of Contents

(I) General Experimental Section

S2

(II) NMR Spectra of Compounds $\mathbf{2 b - 5}$

S3

(III)X-ray Crystal Structural Data of $\mathbf{4 a}$

S36 


\section{(I) General Experimental Section}

IR spectra were obtained in $\mathrm{CH}_{2} \mathrm{Cl}_{2}$ solution. ${ }^{1} \mathrm{H}$ NMR and ${ }^{13} \mathrm{C}-\mathrm{NMR}$ spectra were obtained with a Bruker 300 spectrometer. High Resolution Mass spectra were obtained at Korea Basic Science Institute (Dae Gu). 

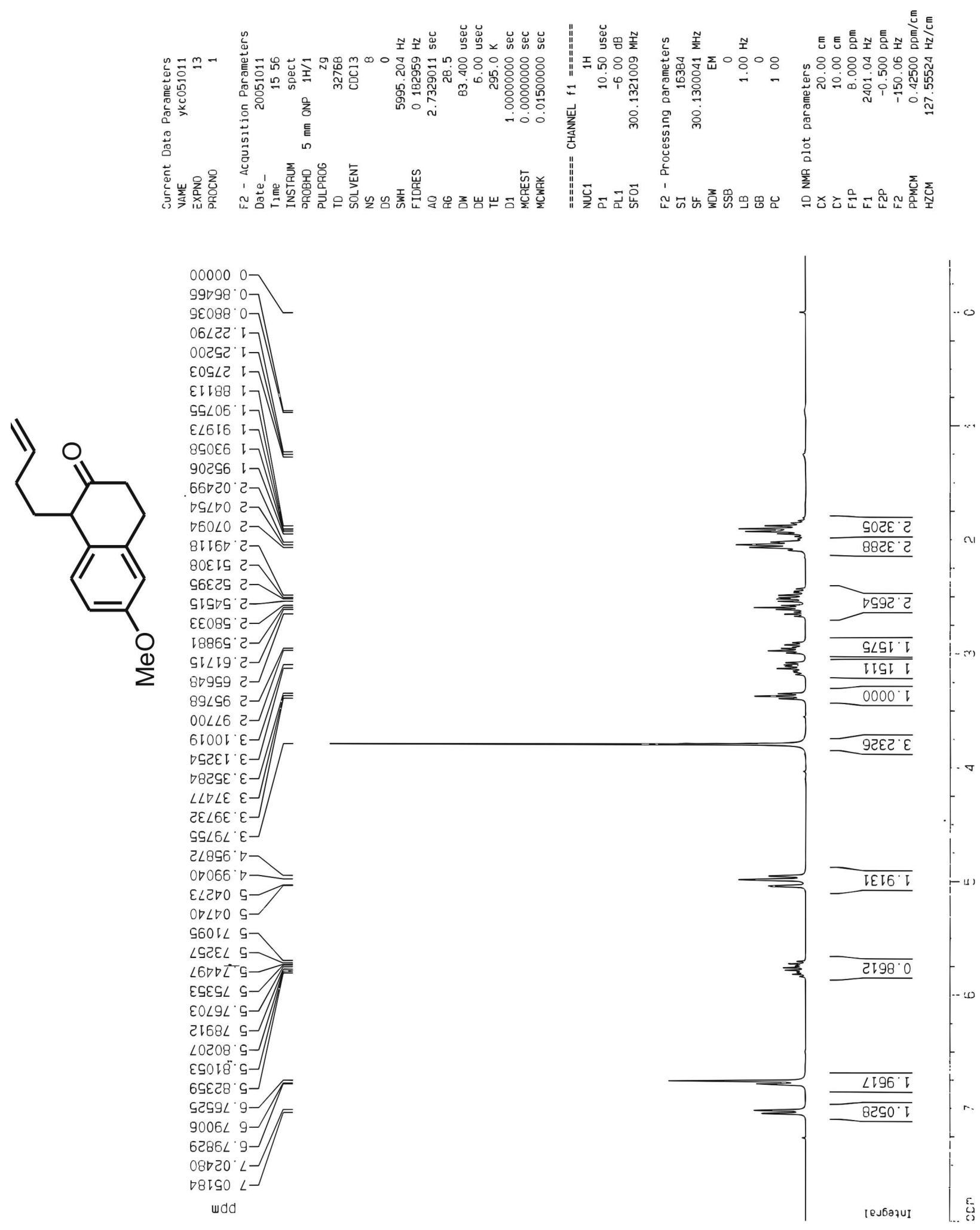

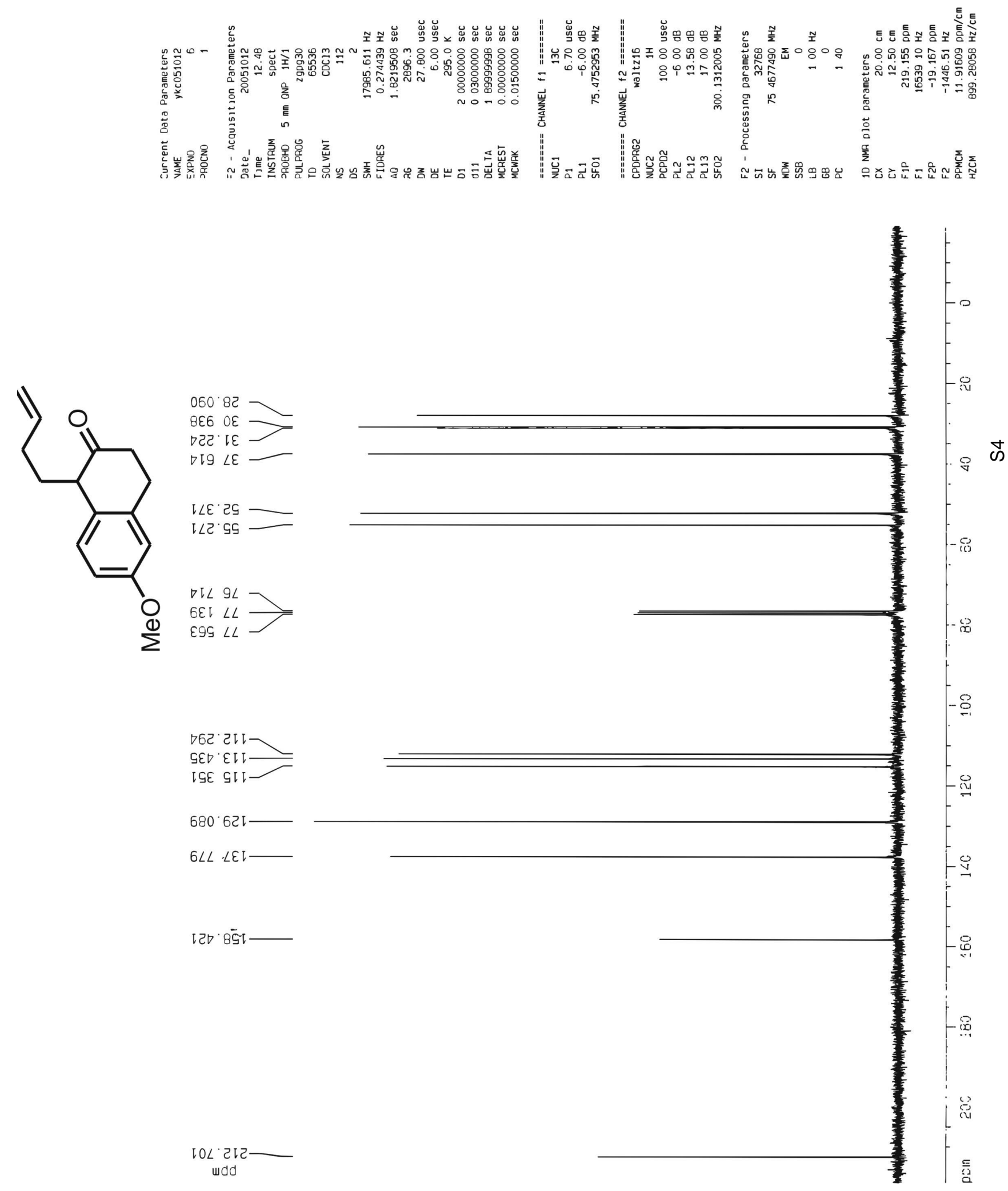

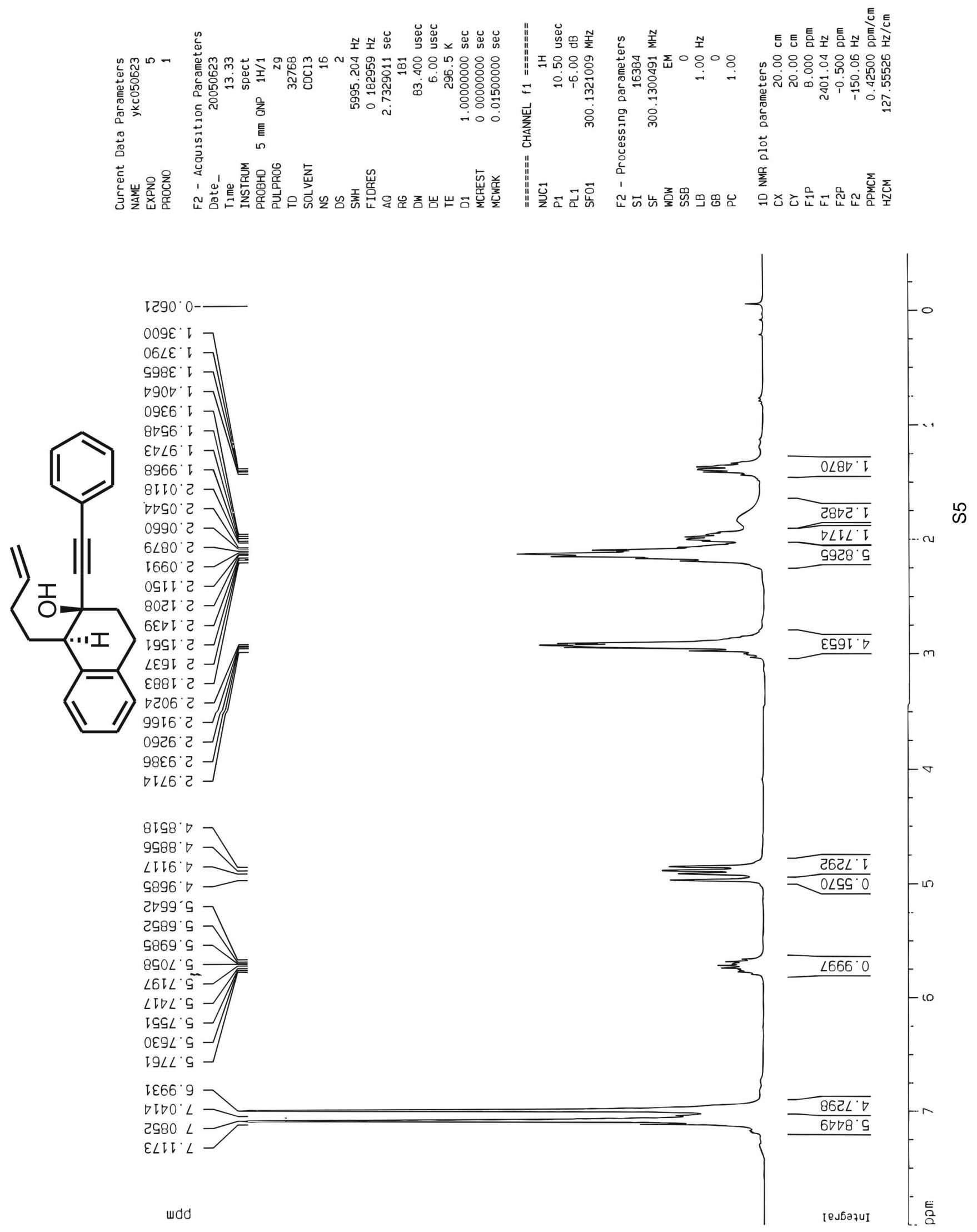

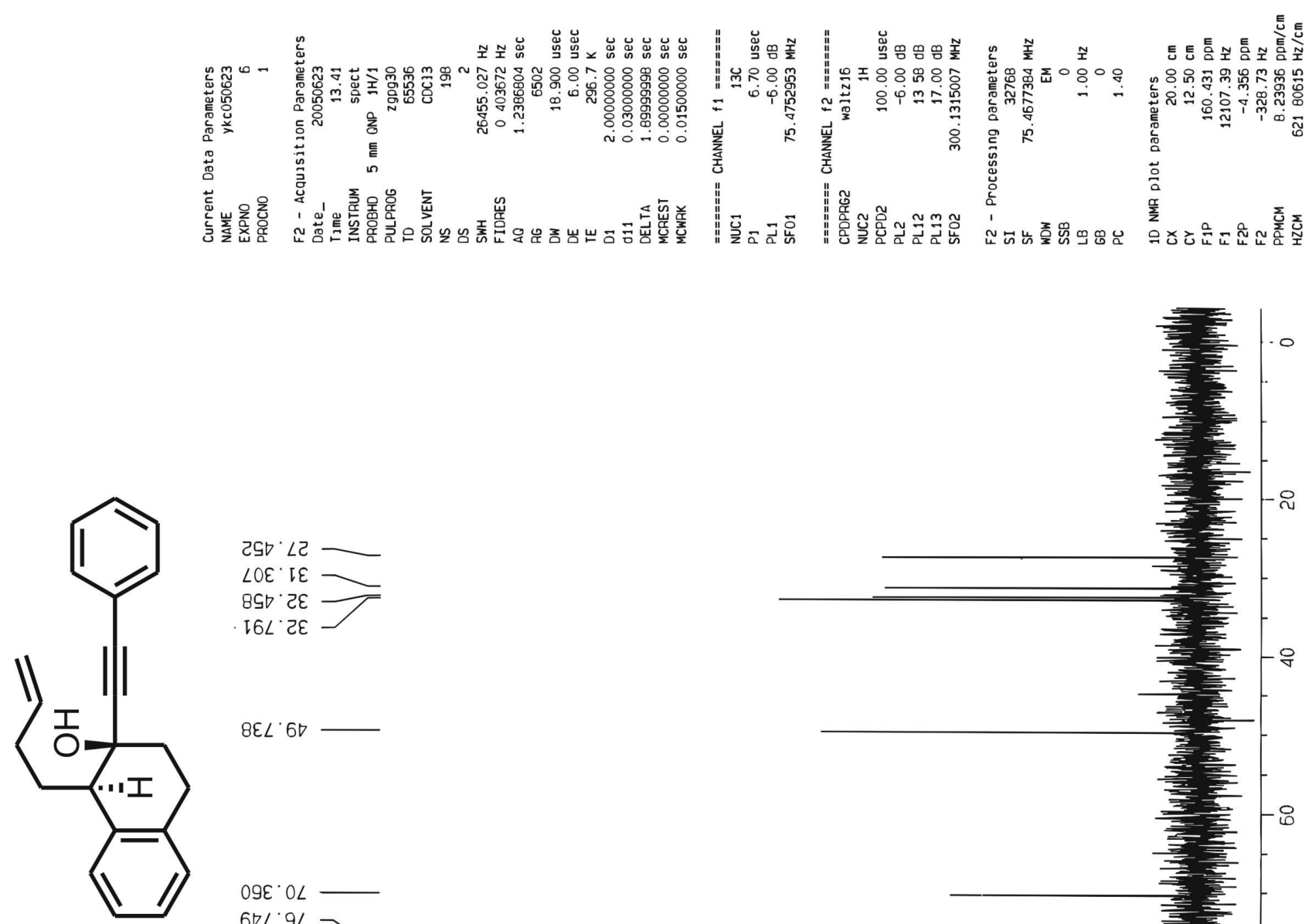

$2 S D^{\circ} \angle Z-$

$\angle O E^{\prime}$ IE

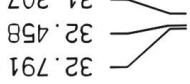

$8 \varepsilon L \cdot 6 \nabla$

.

O9E. $0 L$

$6 \nabla L \cdot 9 L$

$\varepsilon \angle I^{\prime} \angle L$

$969^{\circ} \angle L$

टा0.

टโ६ ट6

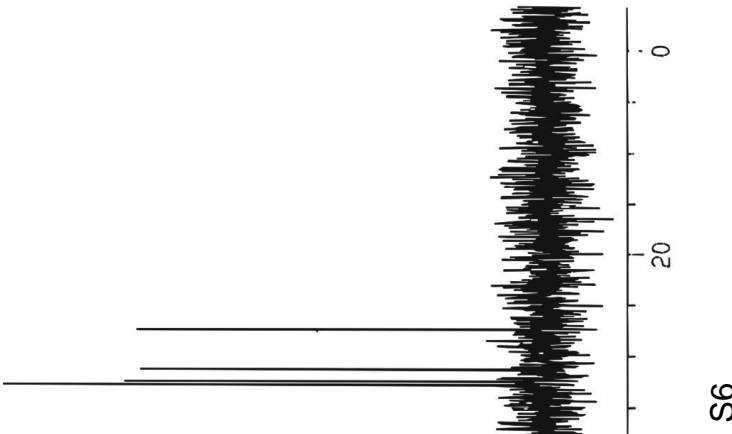

œ

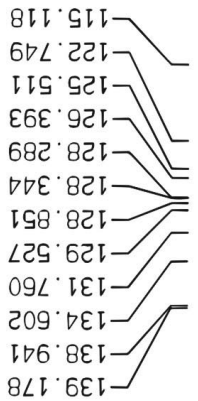



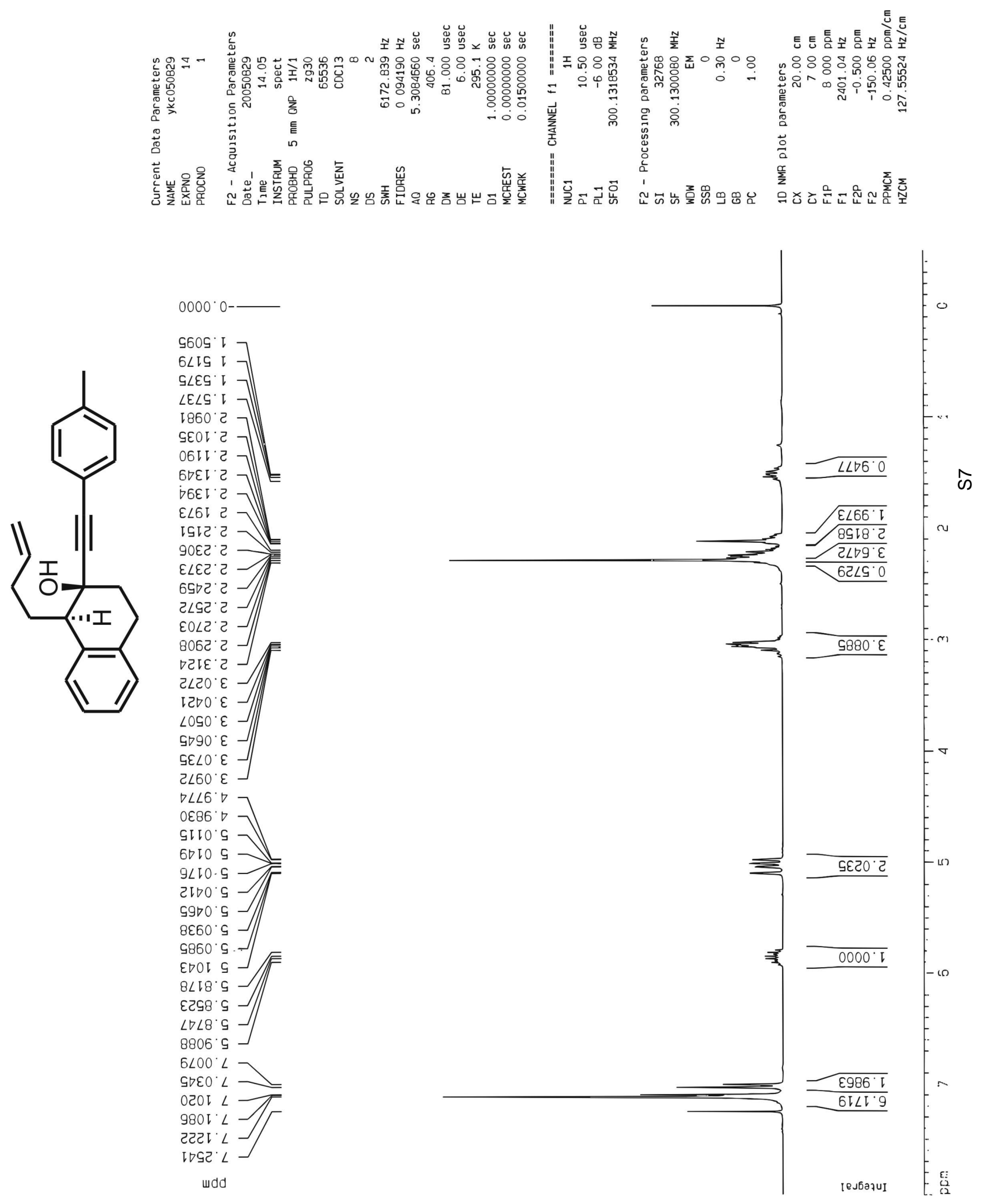

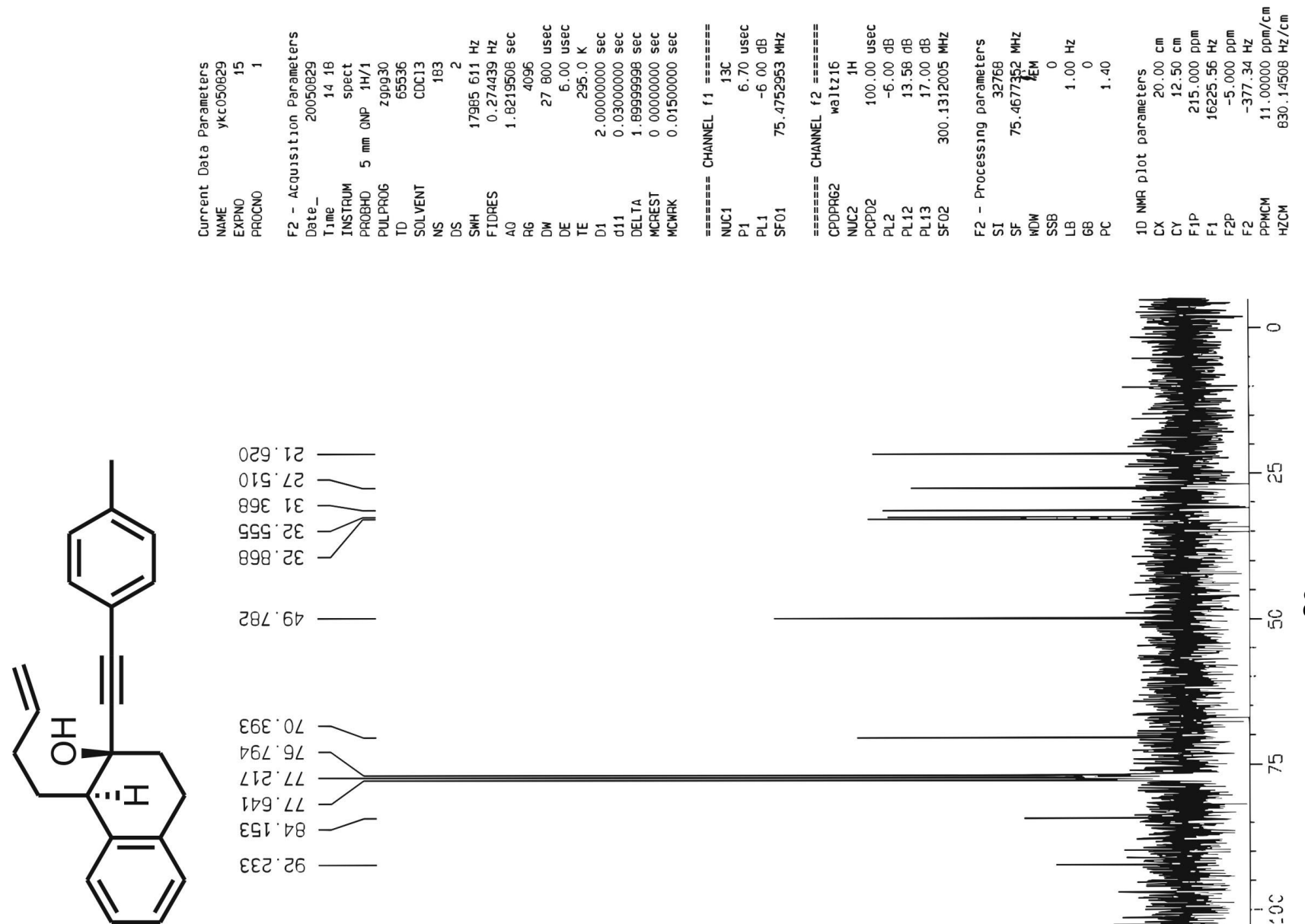

OZ9. I己

OIG $\angle 2-$

$89 \varepsilon$ IE

ज૬વ. ટદ

898. टह -

$28 \angle{ }^{\circ} 6 \square$

EธE $0 L \longrightarrow$

$\nabla 6 L \cdot 9 L$

$\angle I C \cdot \angle L$

$\operatorname{LP} 9^{\circ} L L$

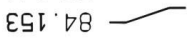

Еहट टб

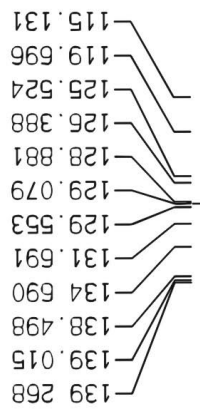

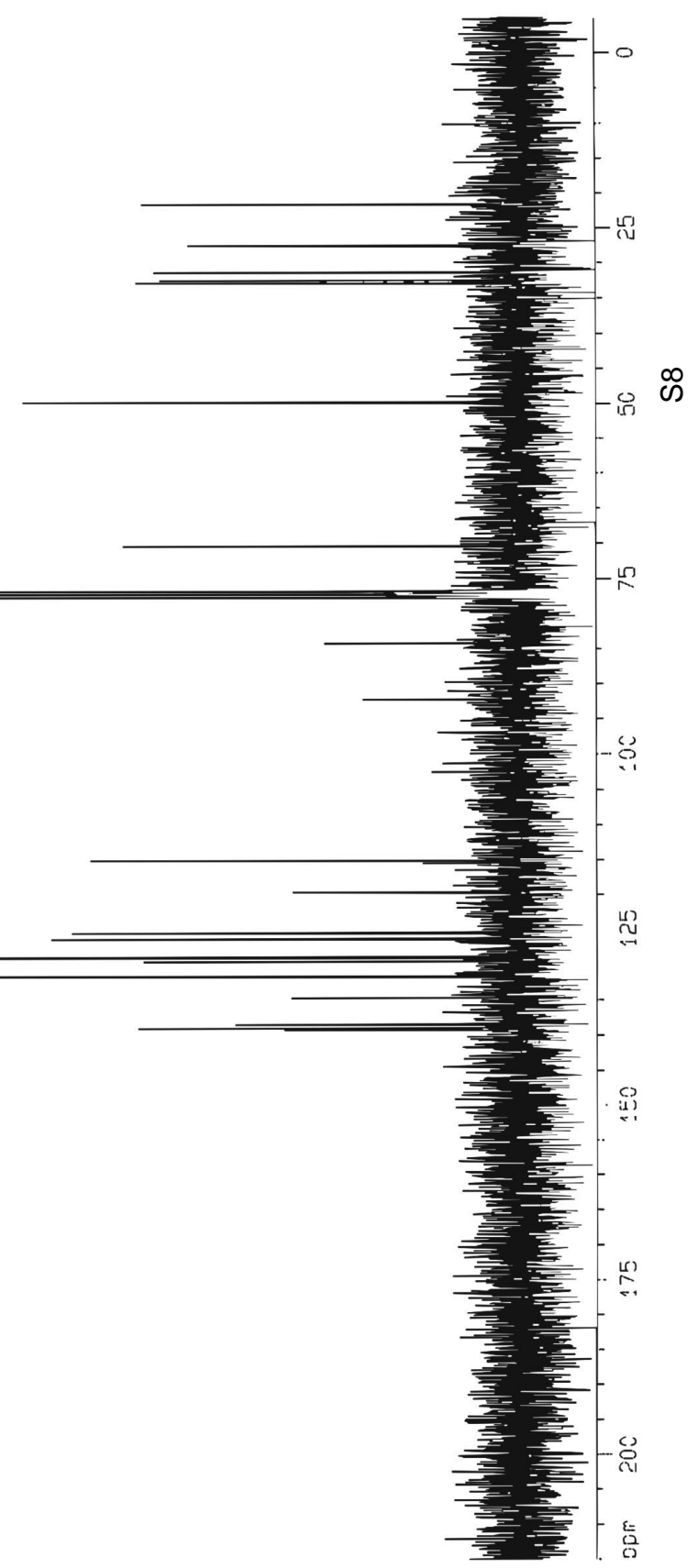



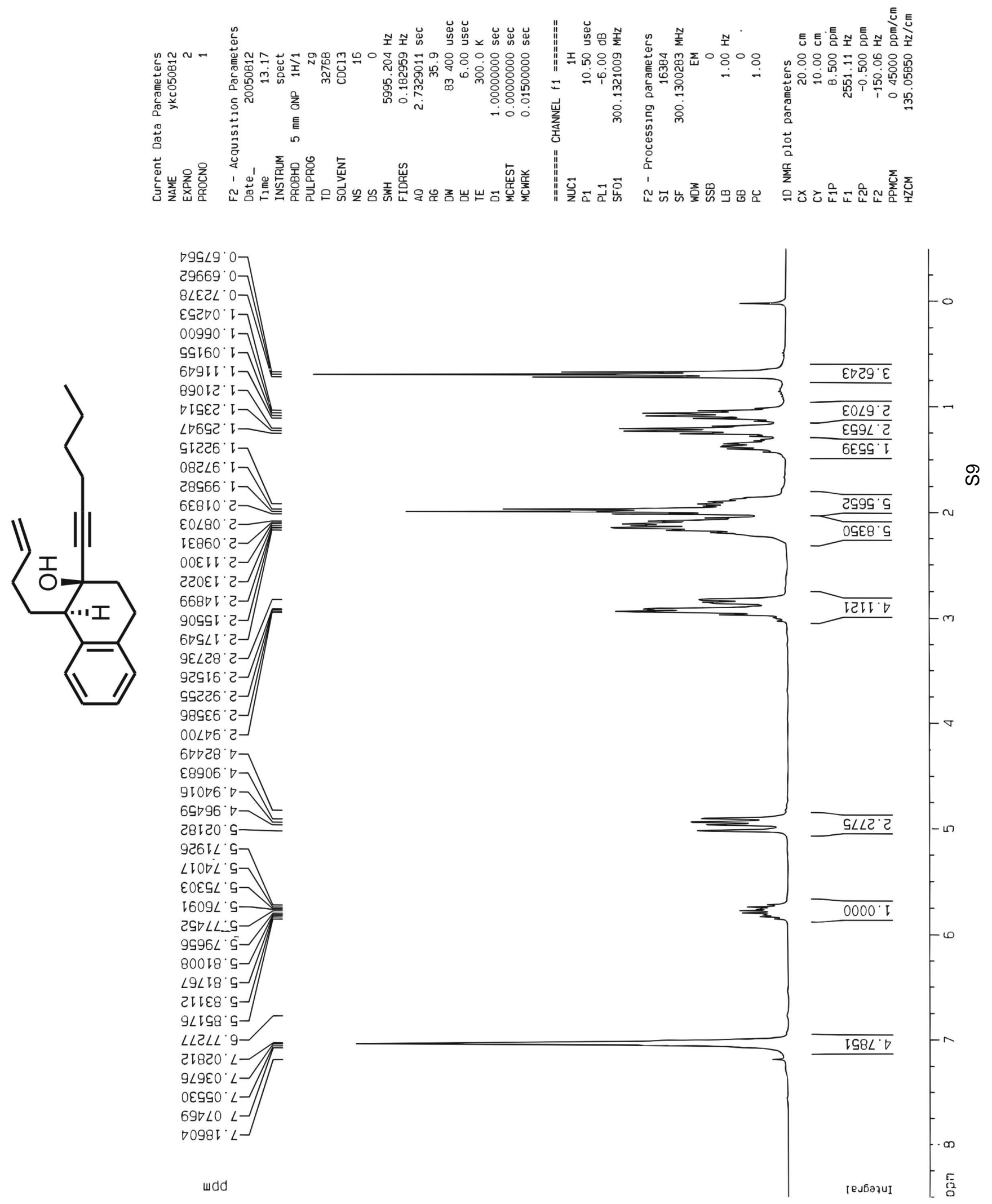

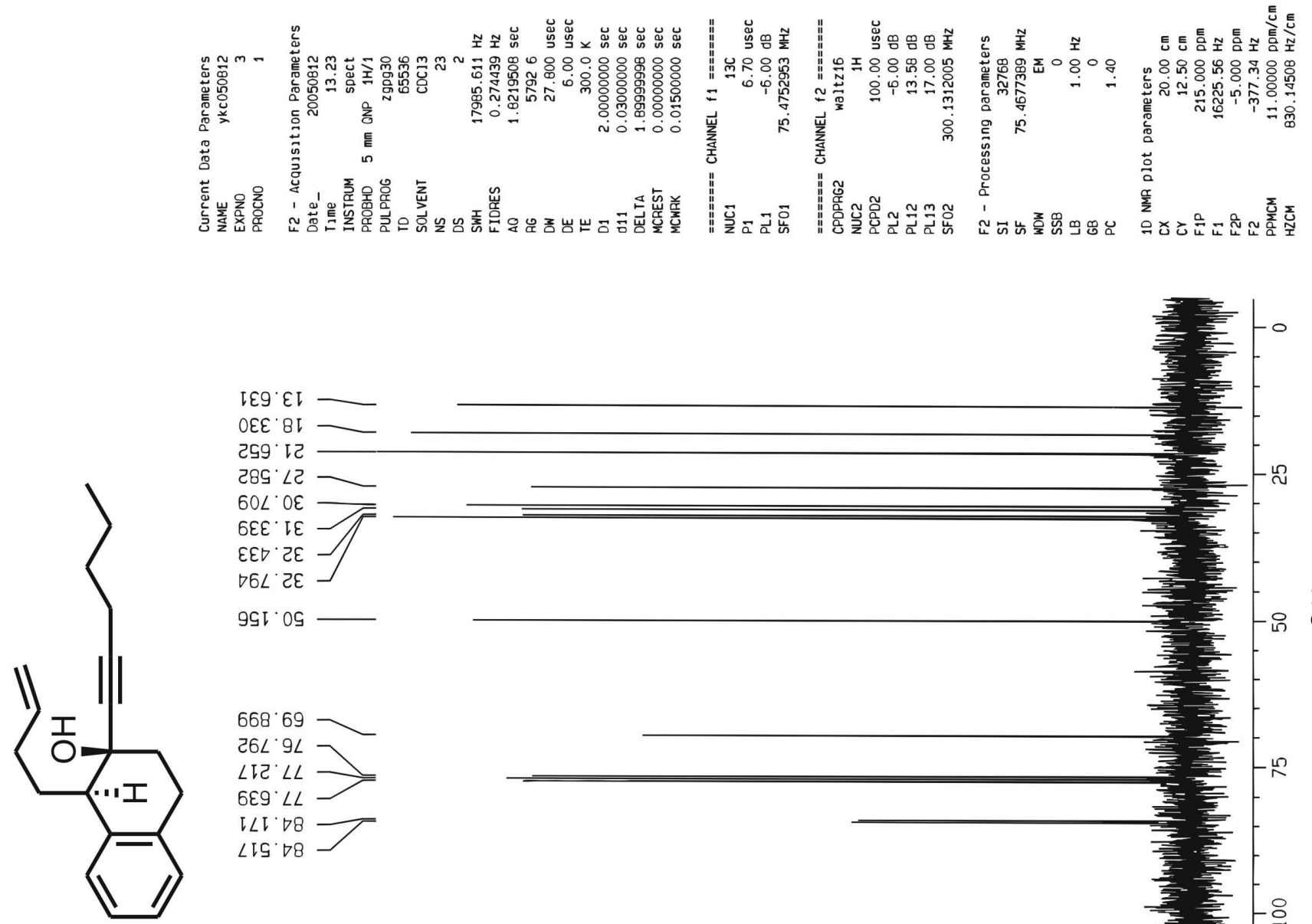

0อ6・ロルー

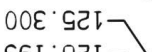
ह6I.9टा$\angle 9 L 82$

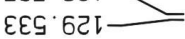

I89. $\nabla \varepsilon \downarrow-$

OSO $6 E I$ 065.6EI-

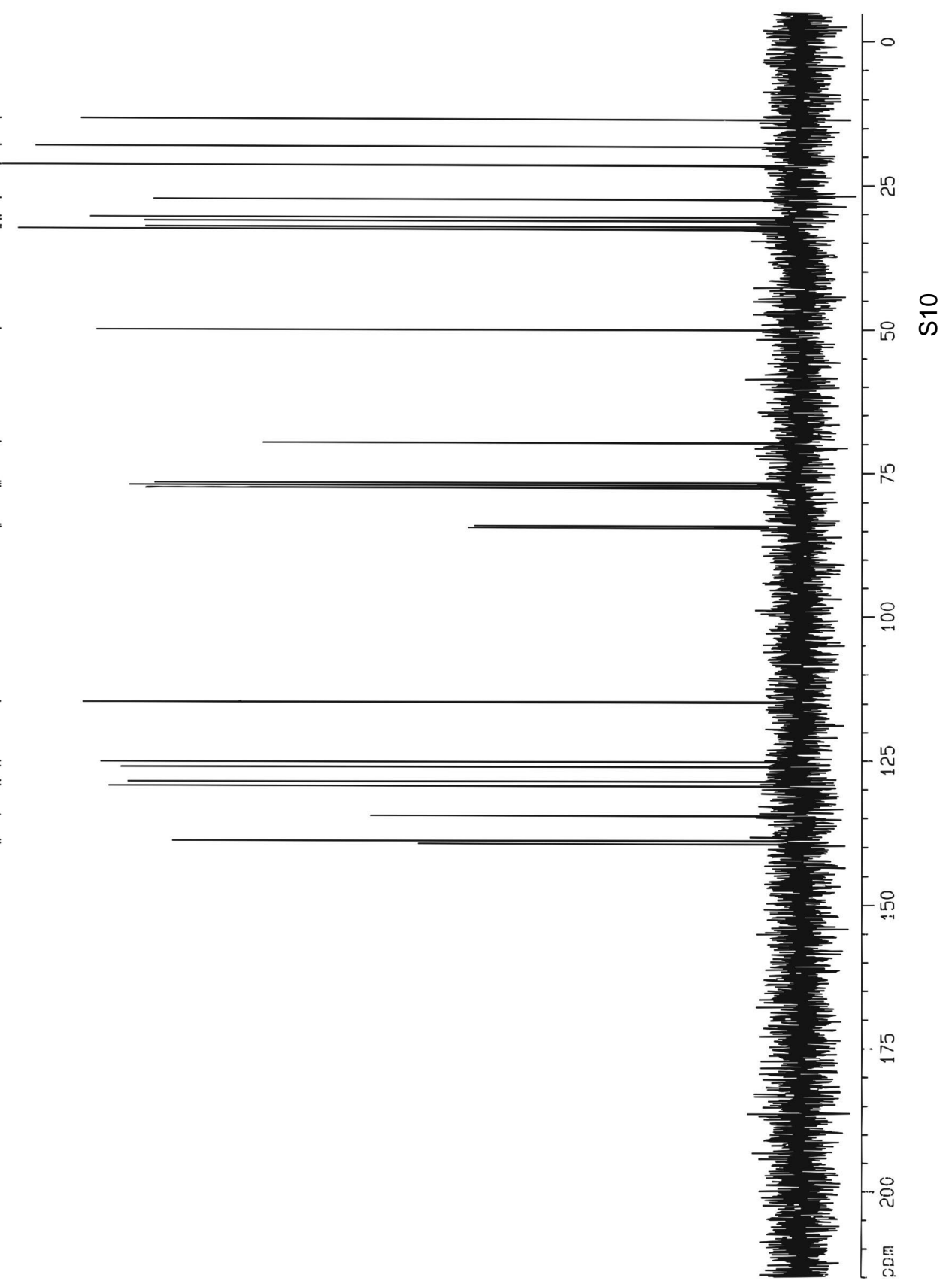



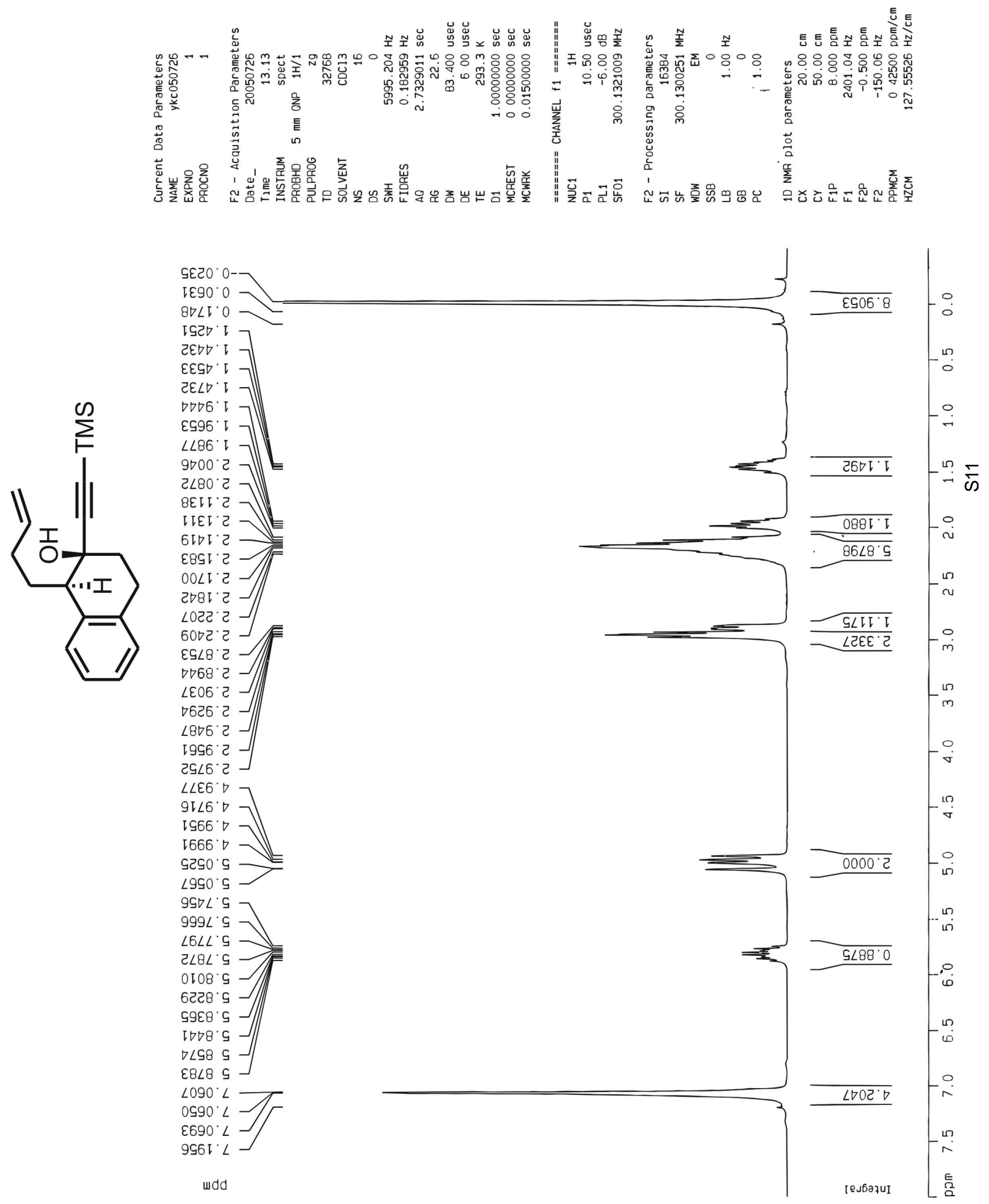

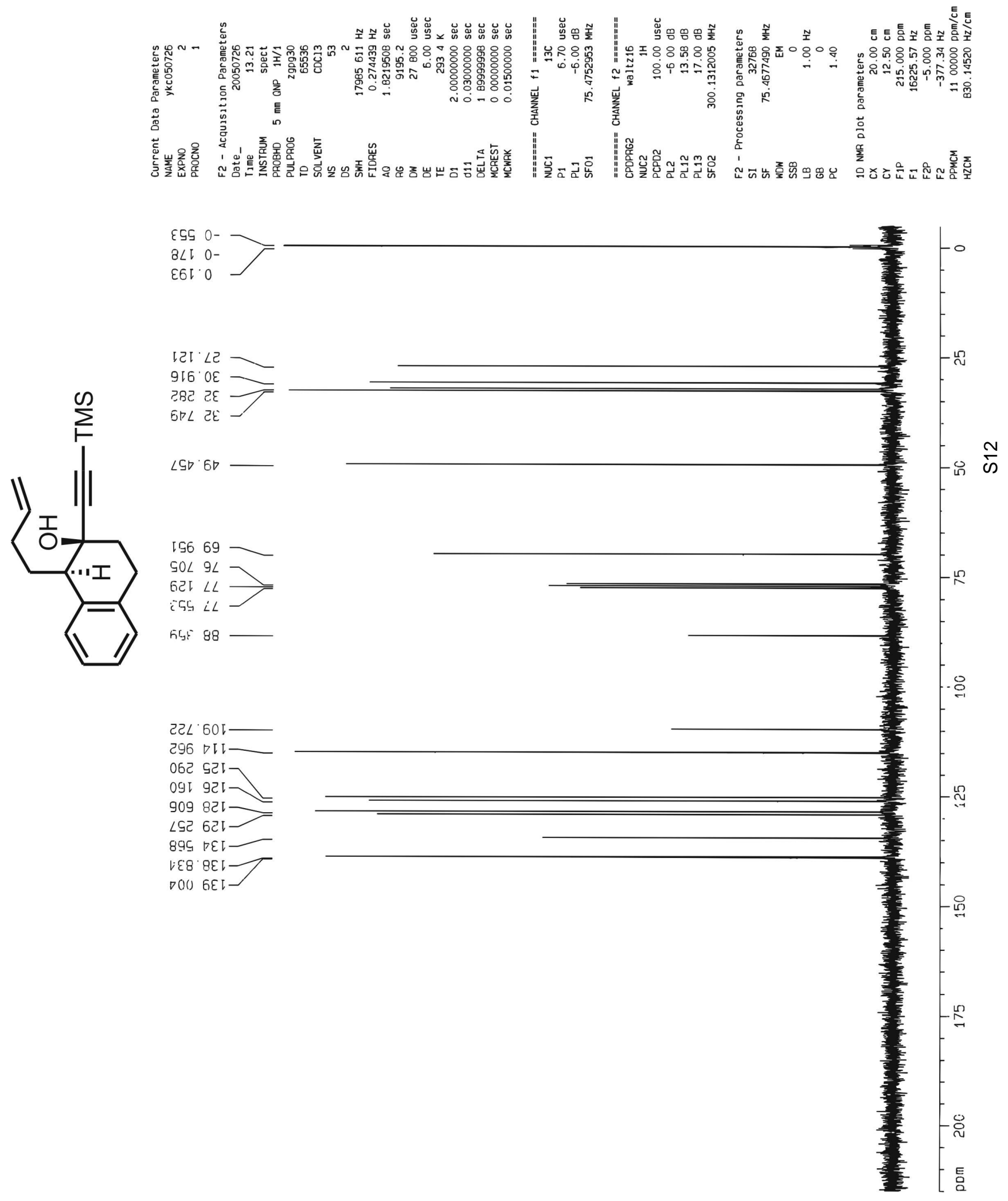


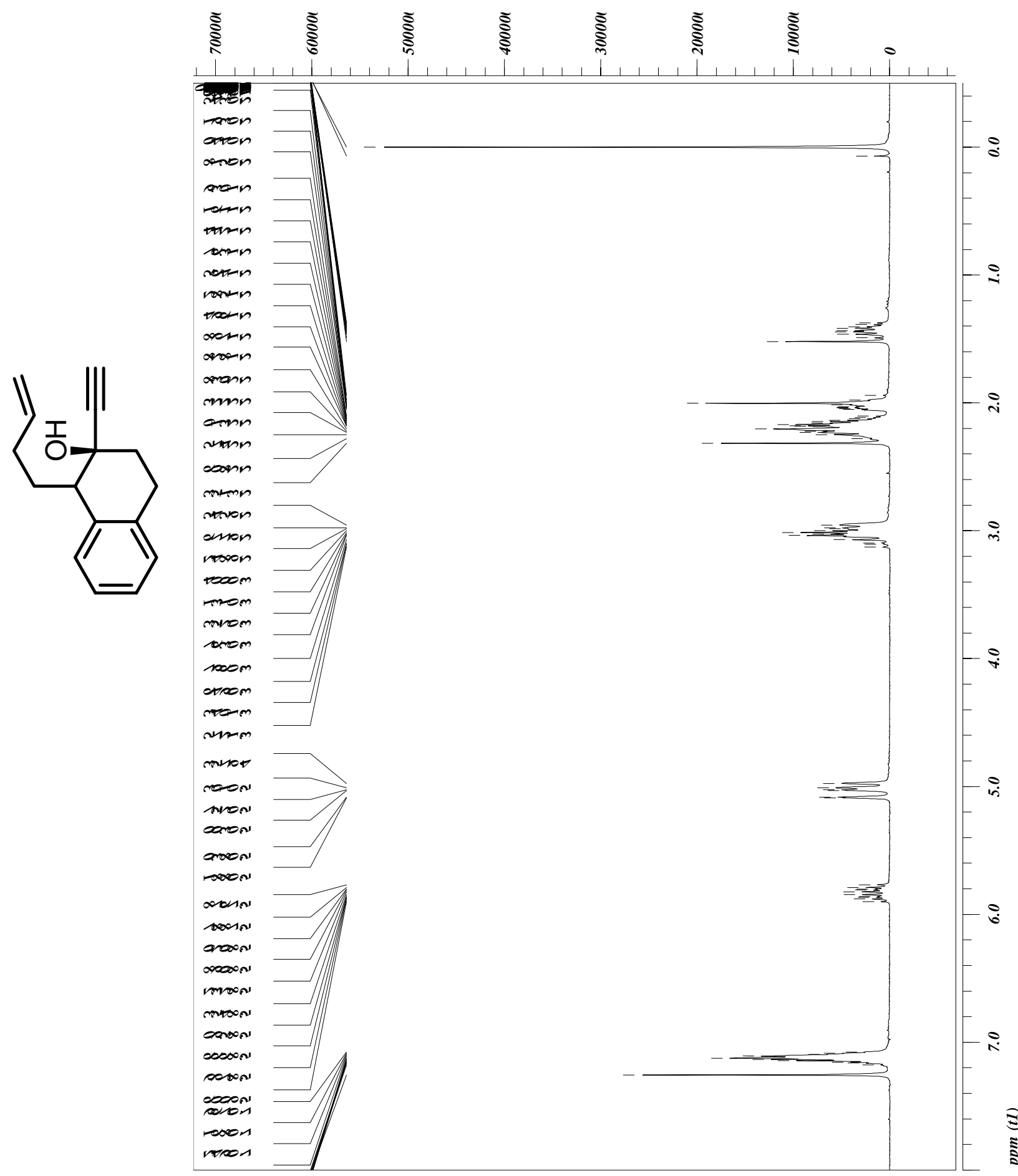




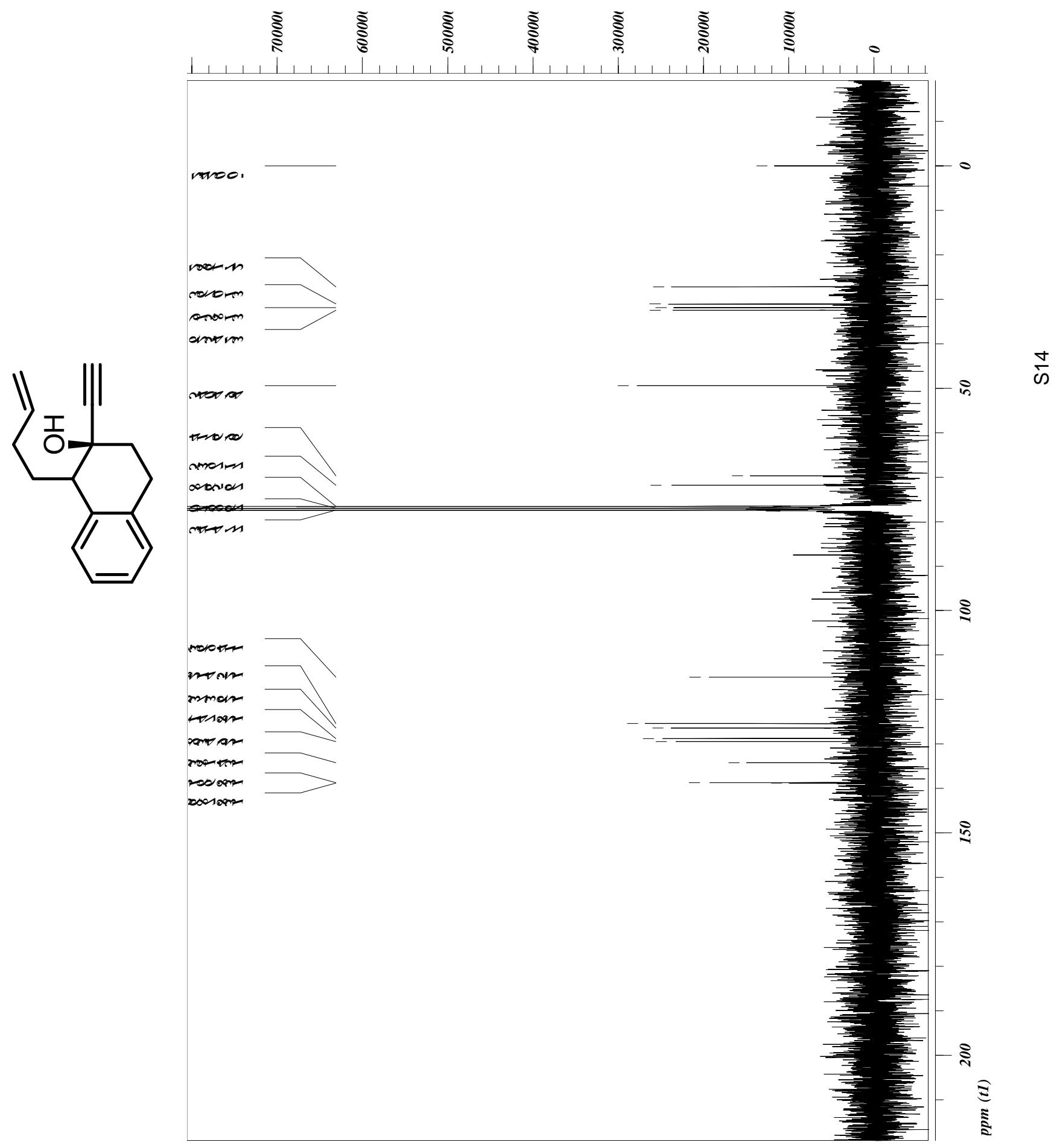



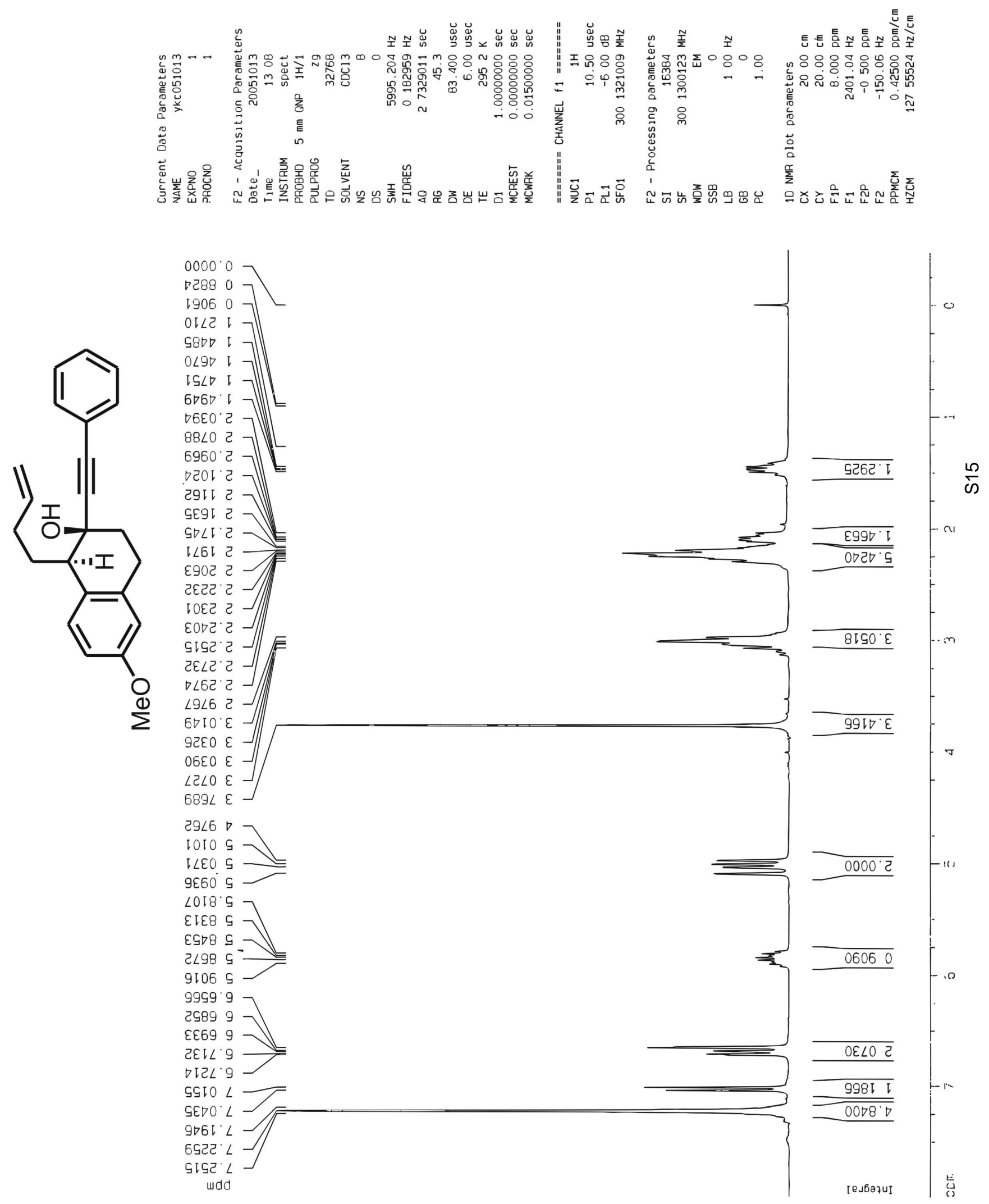

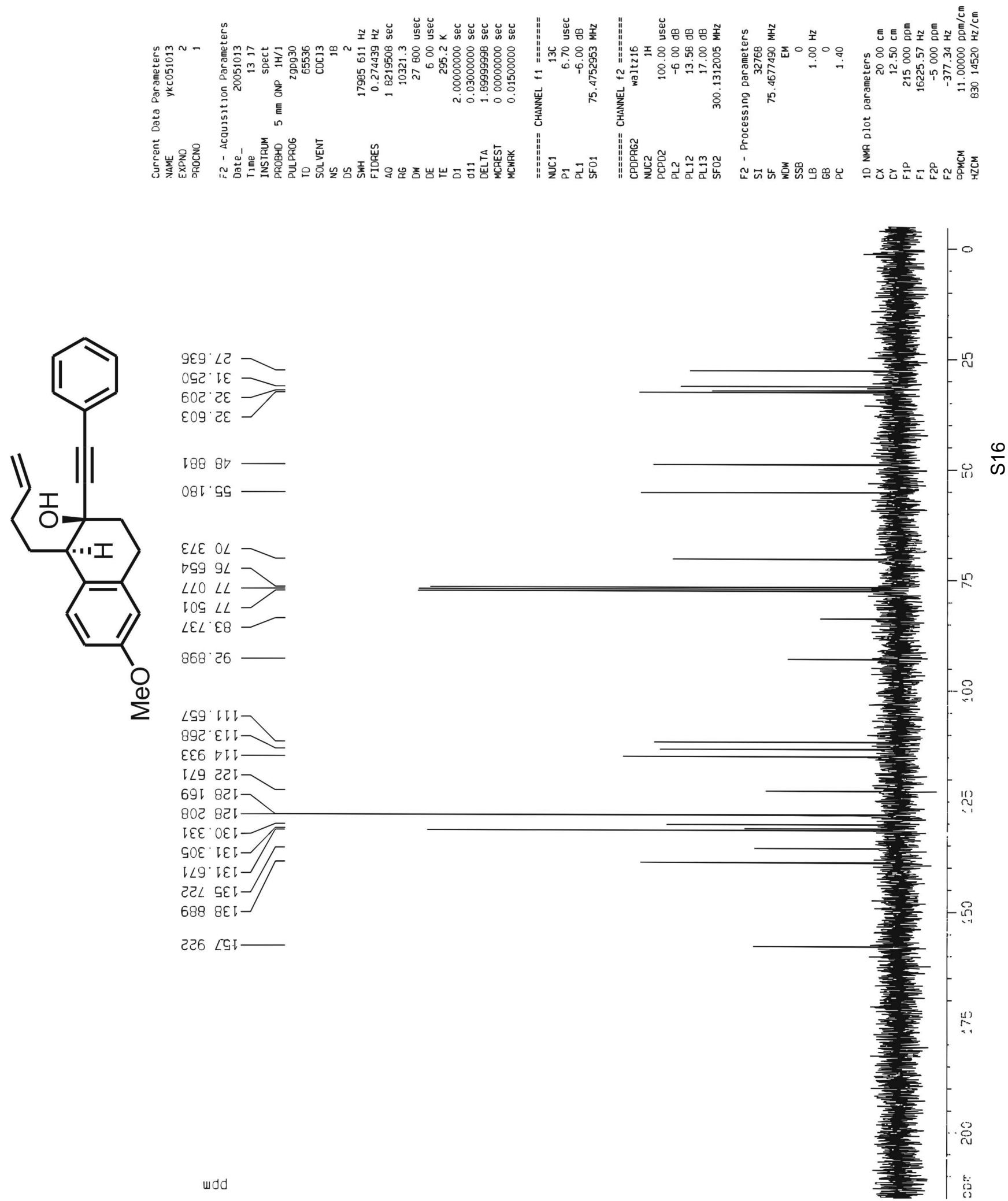

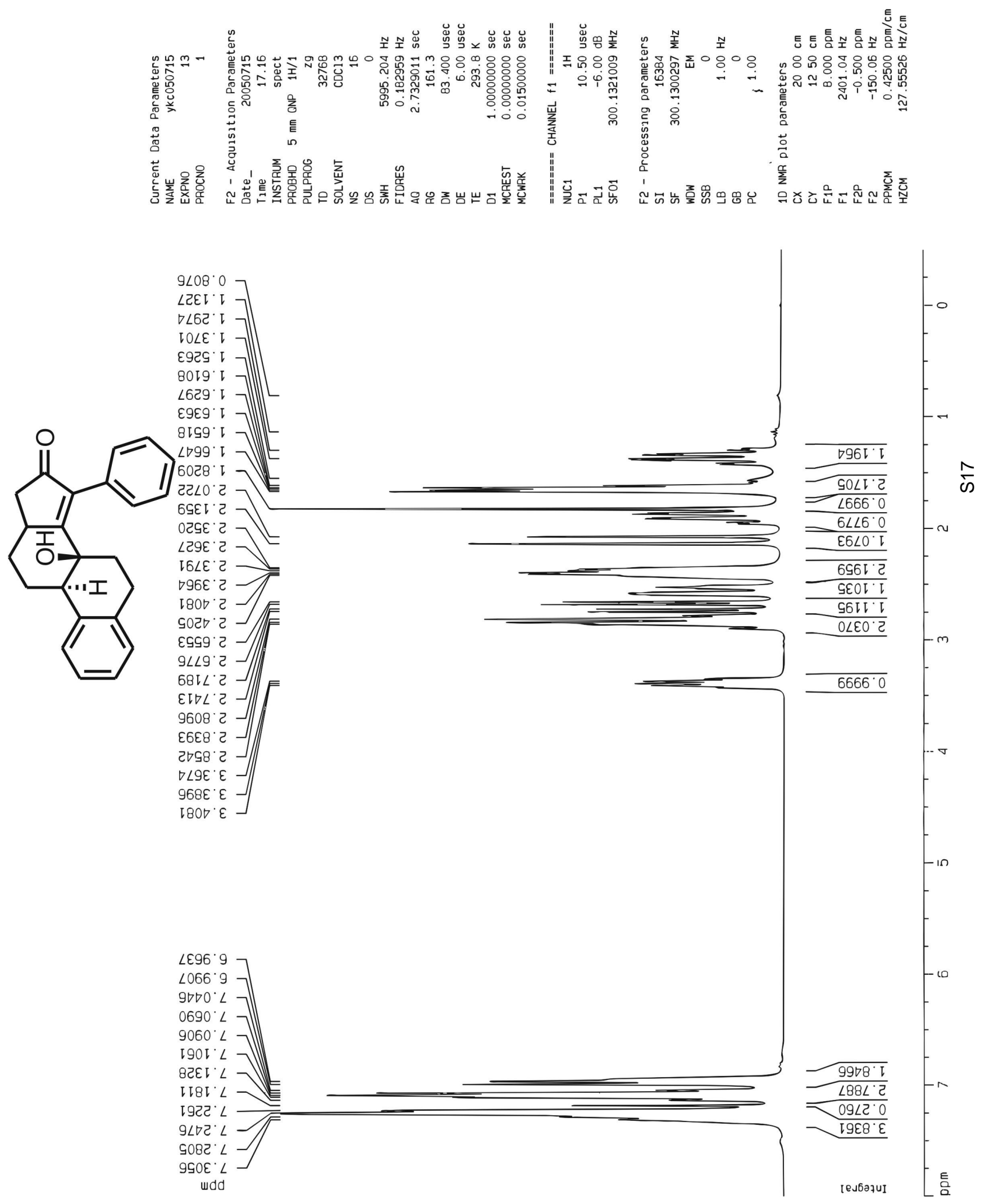

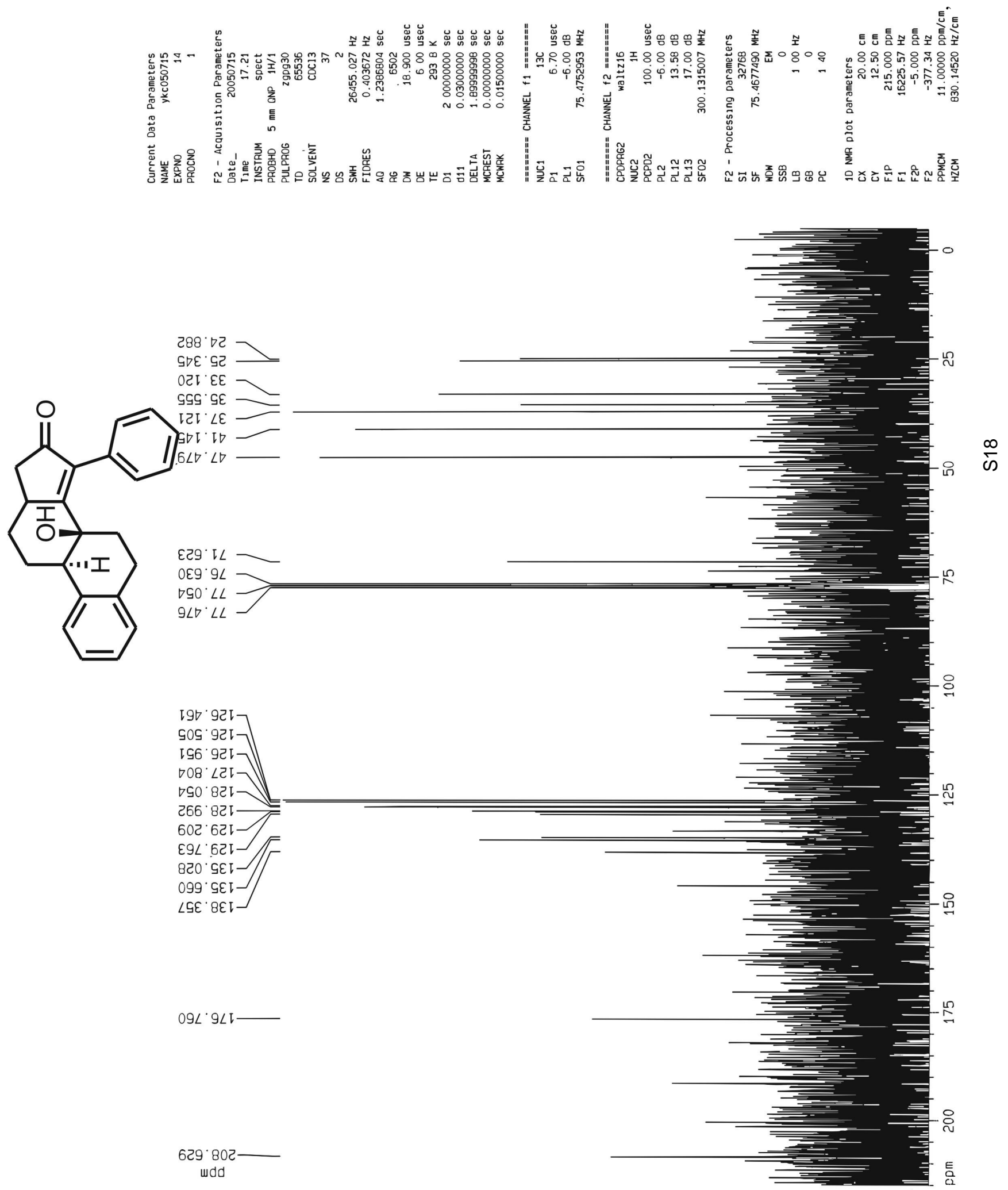


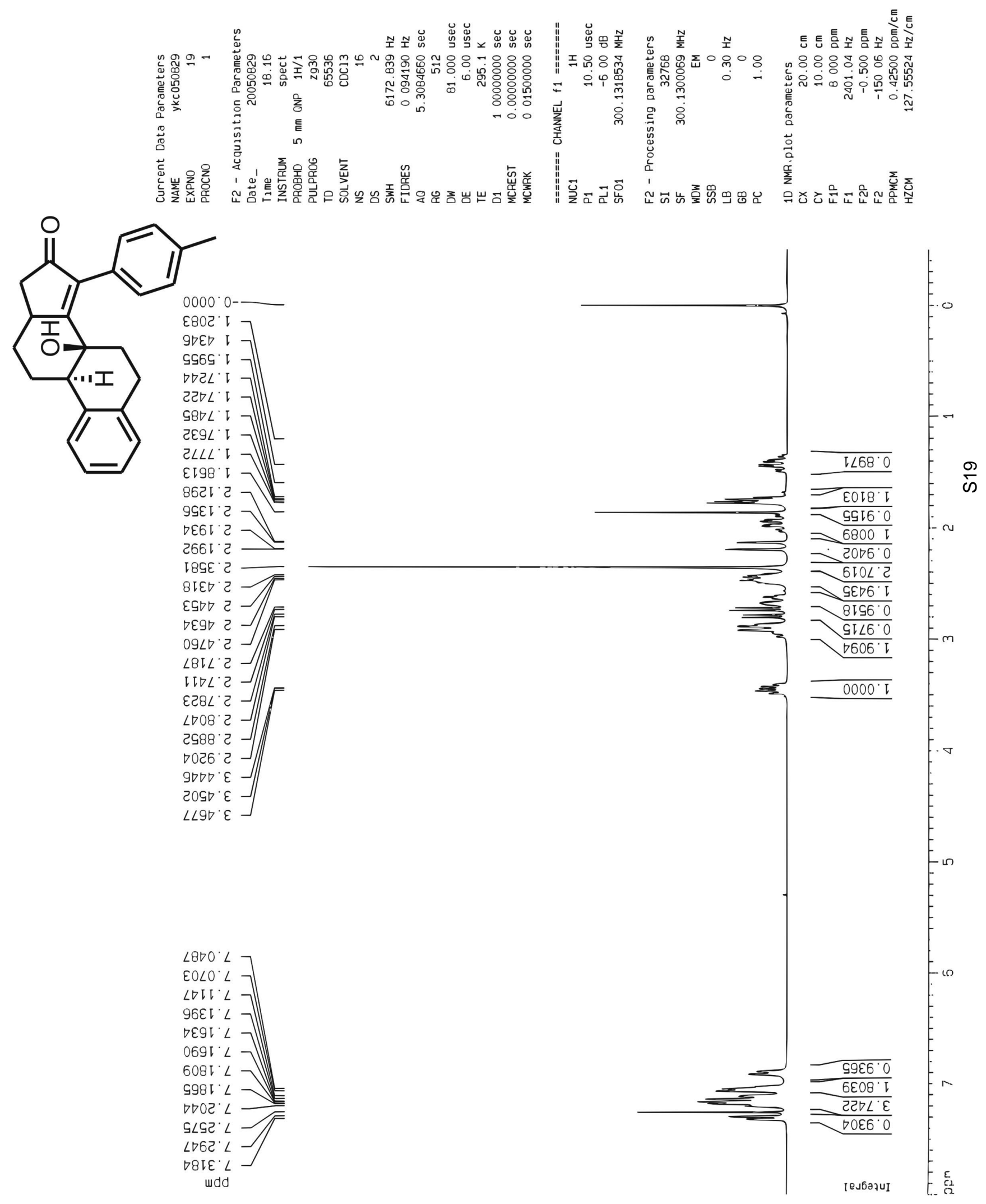



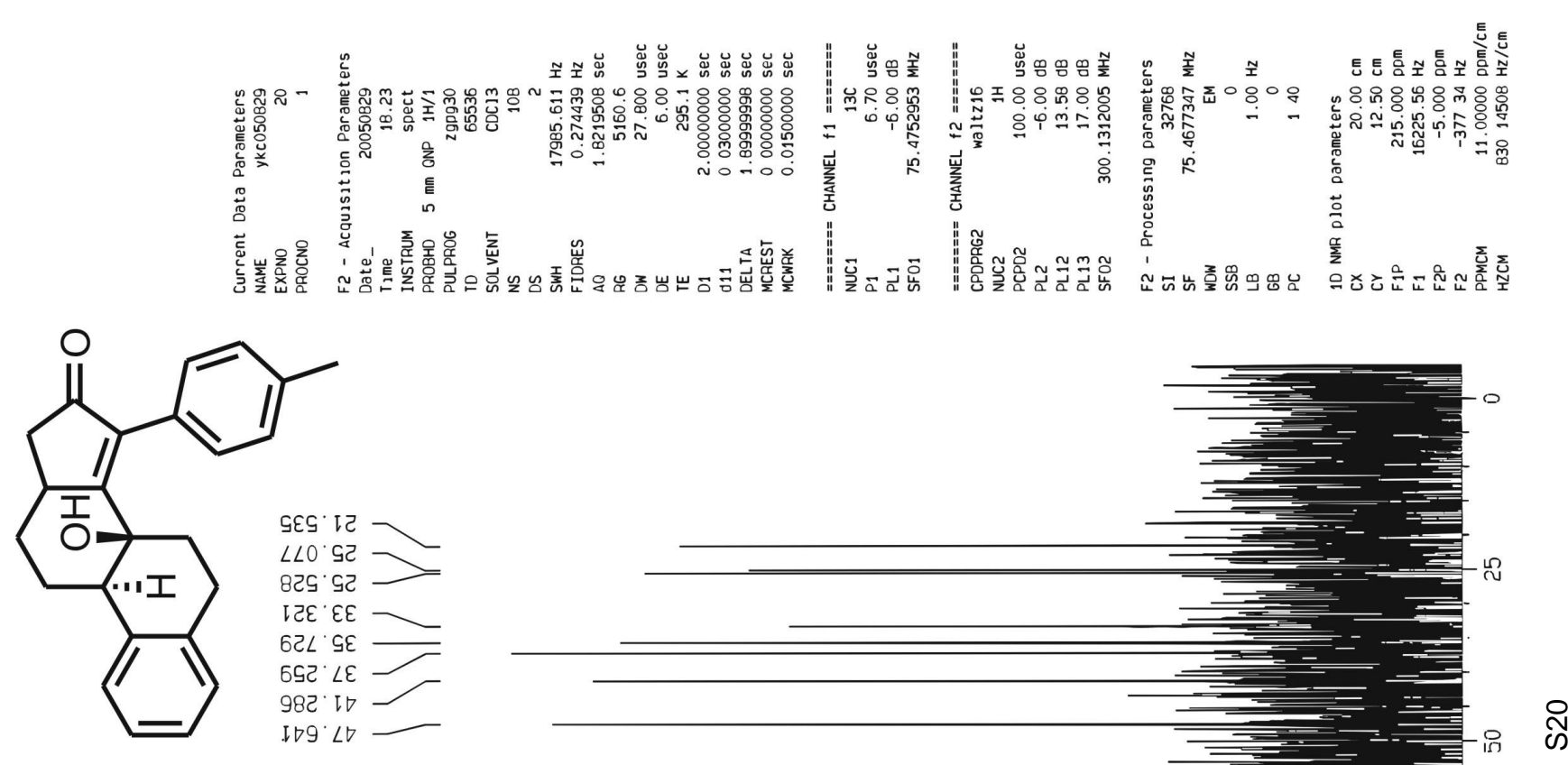

$9 \varepsilon 8^{\circ} \mathrm{L} L$

$\angle 08^{\circ} 9 \angle \longrightarrow$

IEट

$\nabla 9 \theta^{\circ} L L$

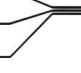

จร9.

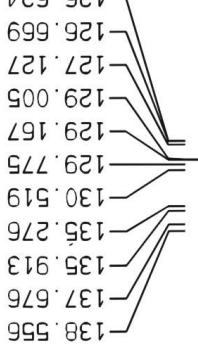

$99 S^{\circ} 8 \varepsilon[-$

$20 L^{\circ} 9 \angle[$ 

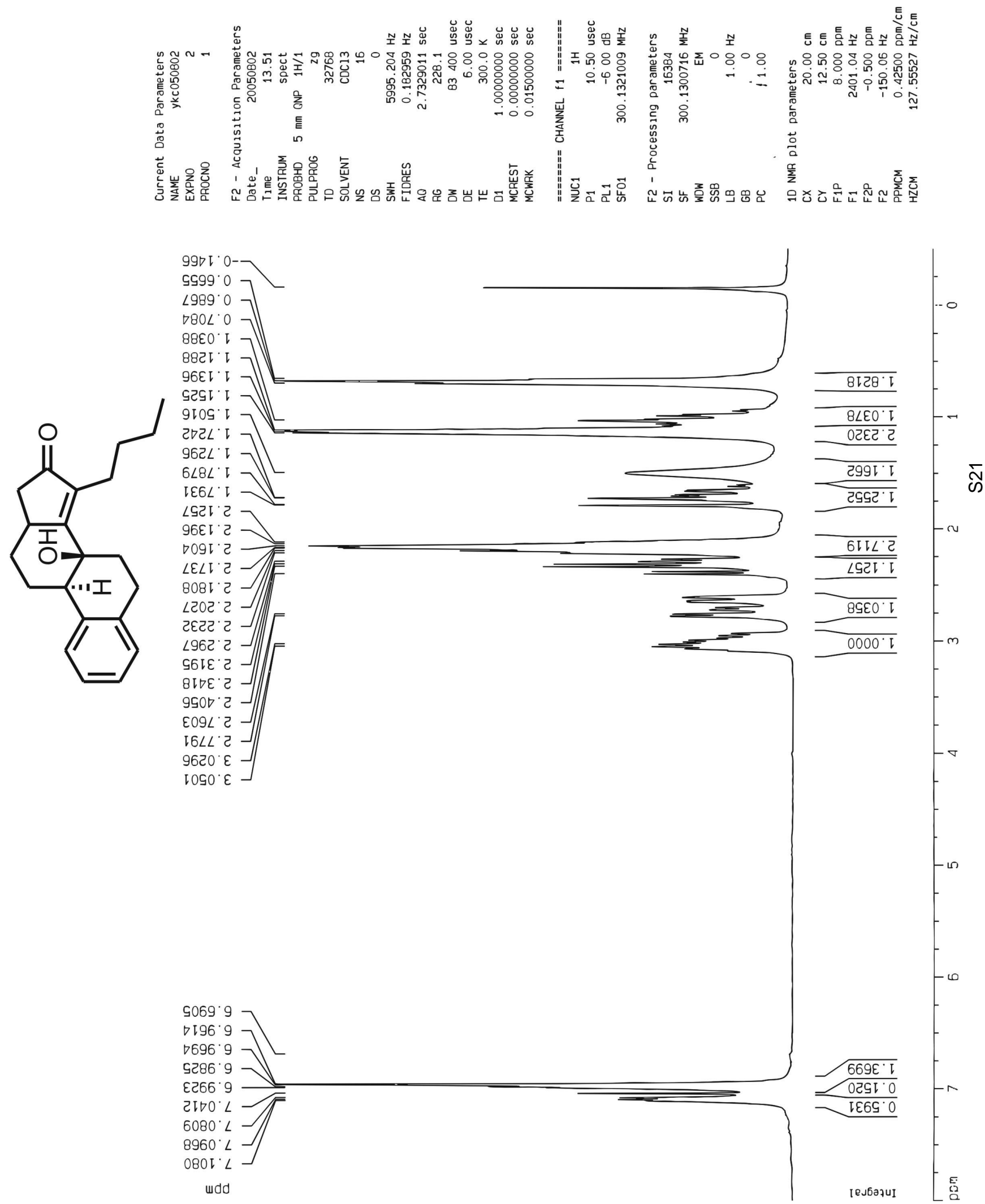

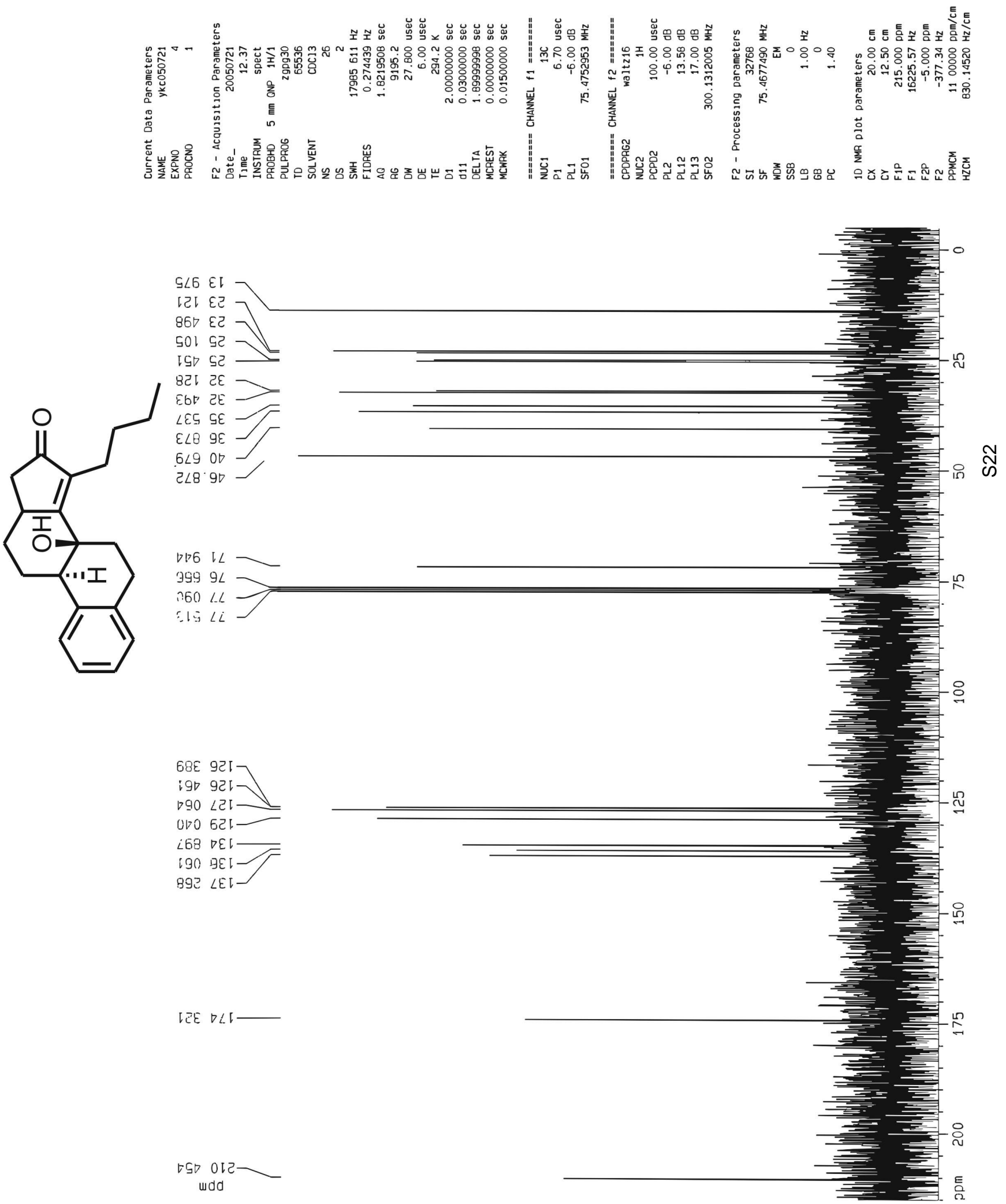

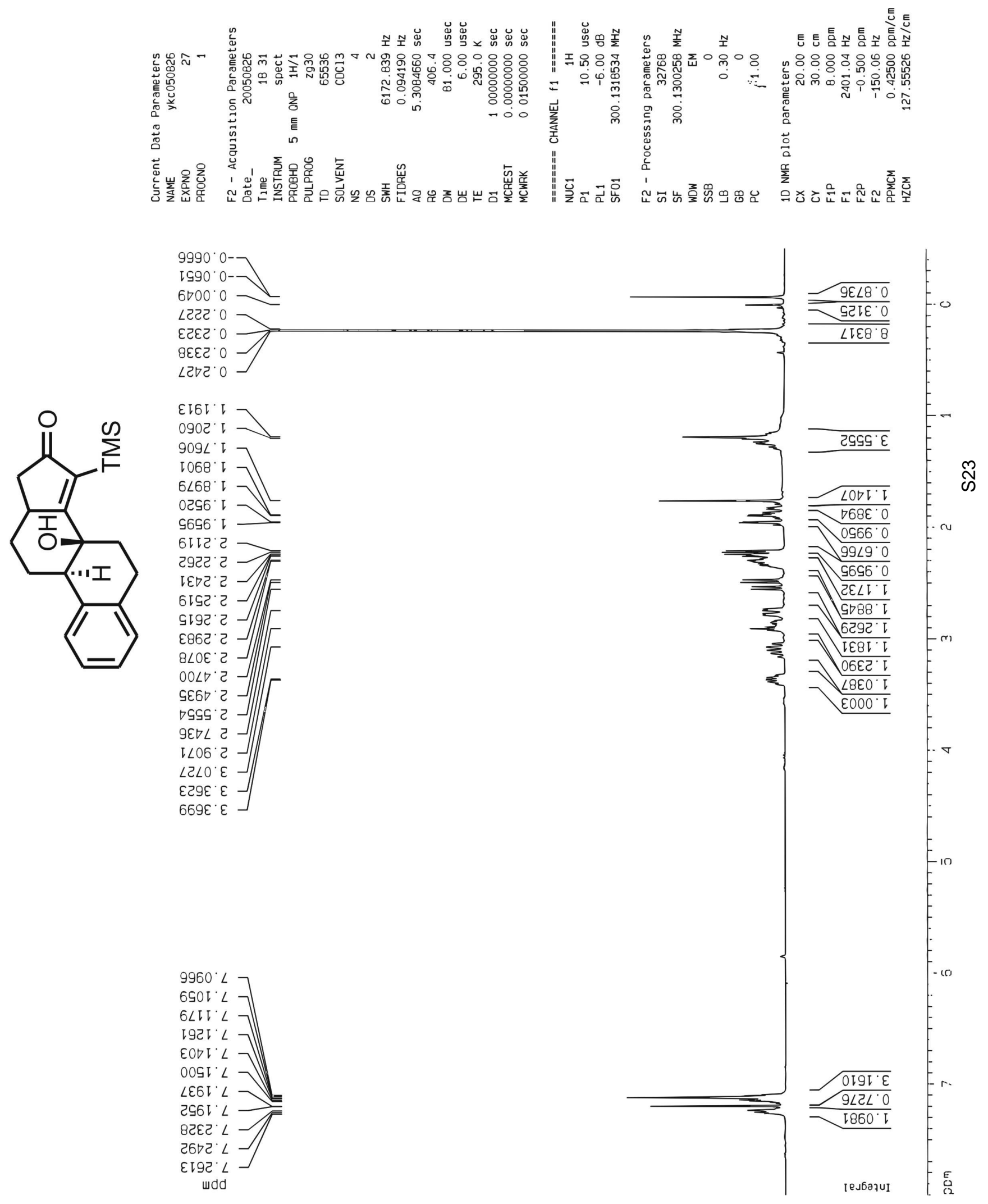

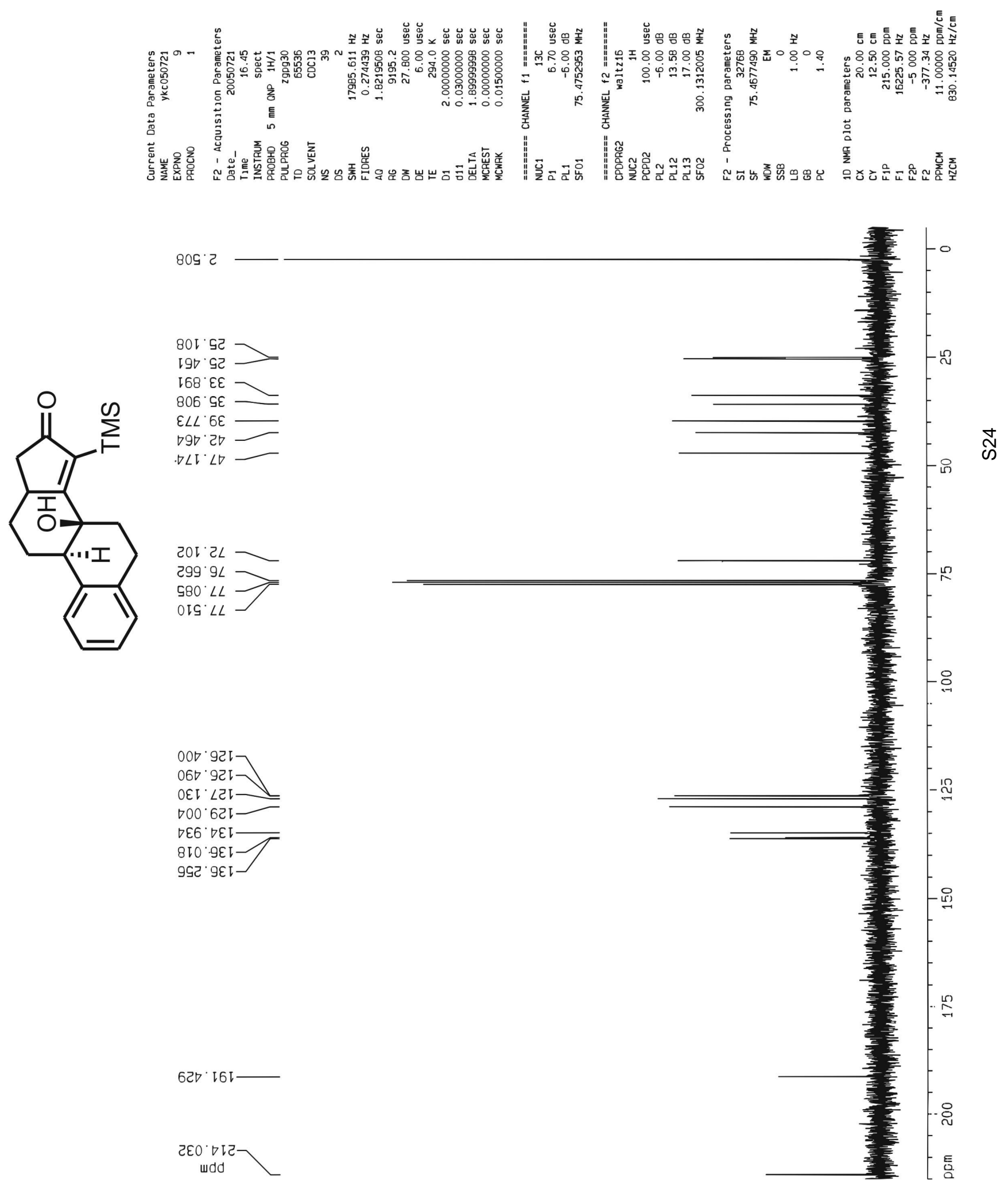


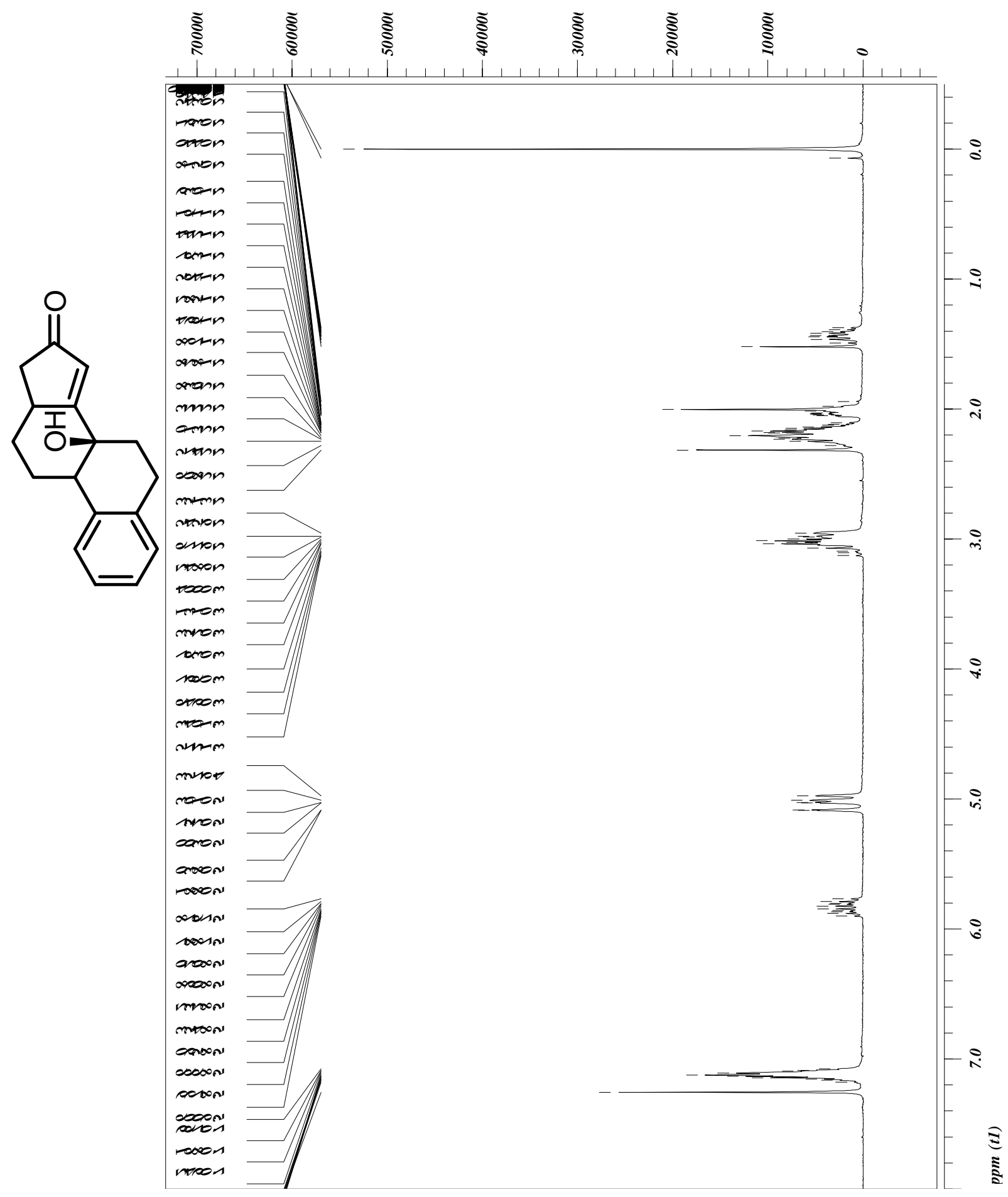




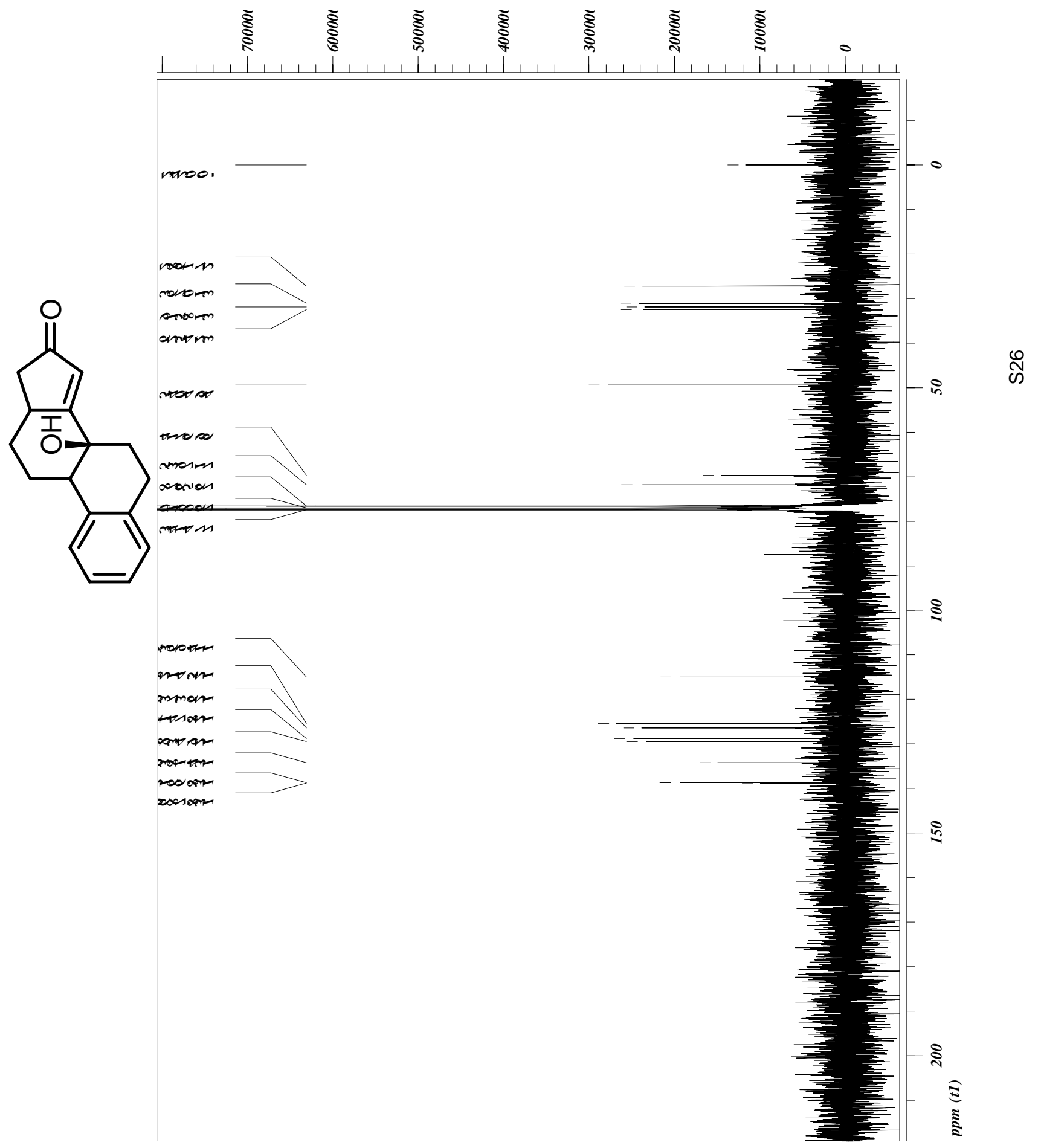




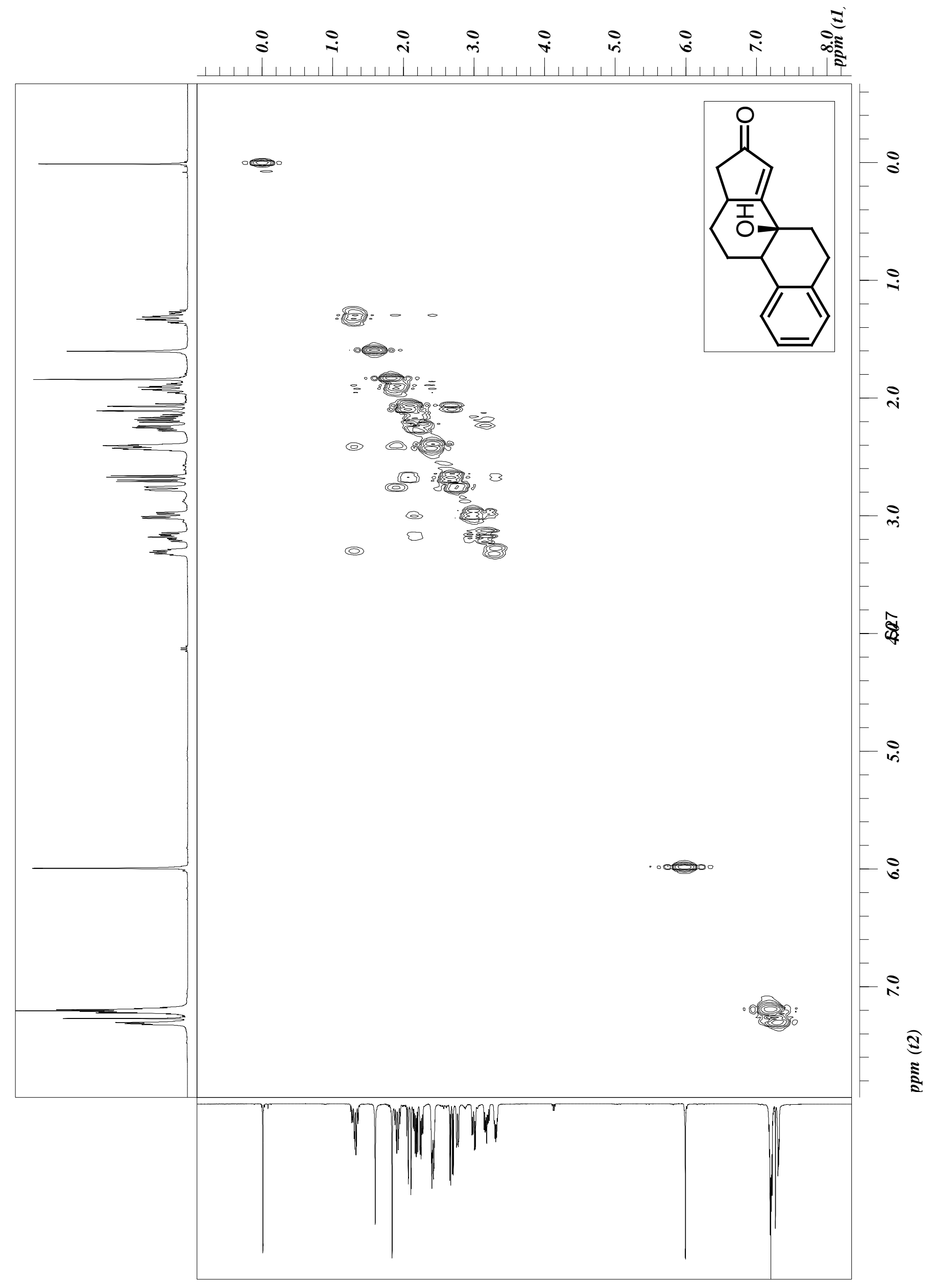



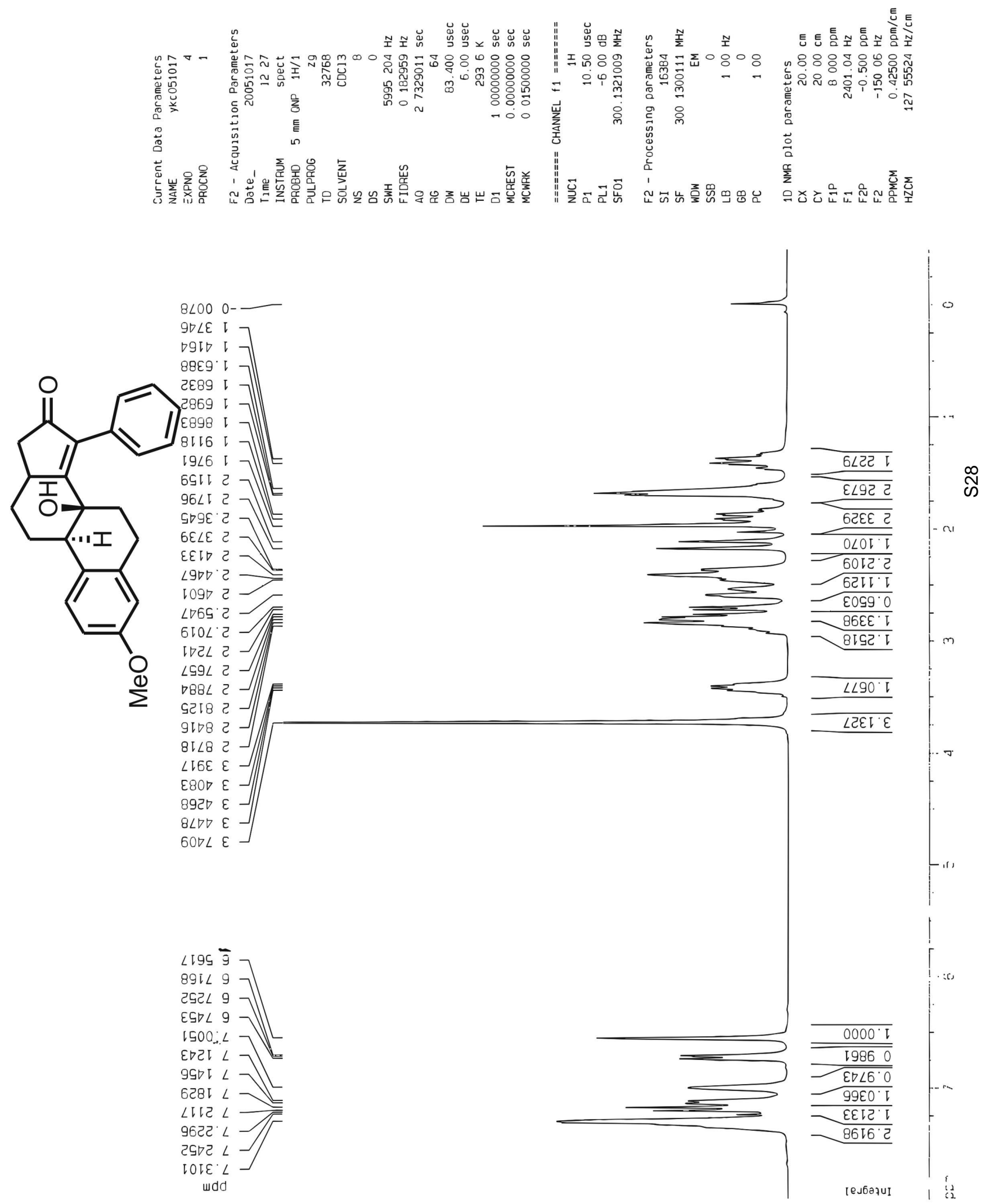

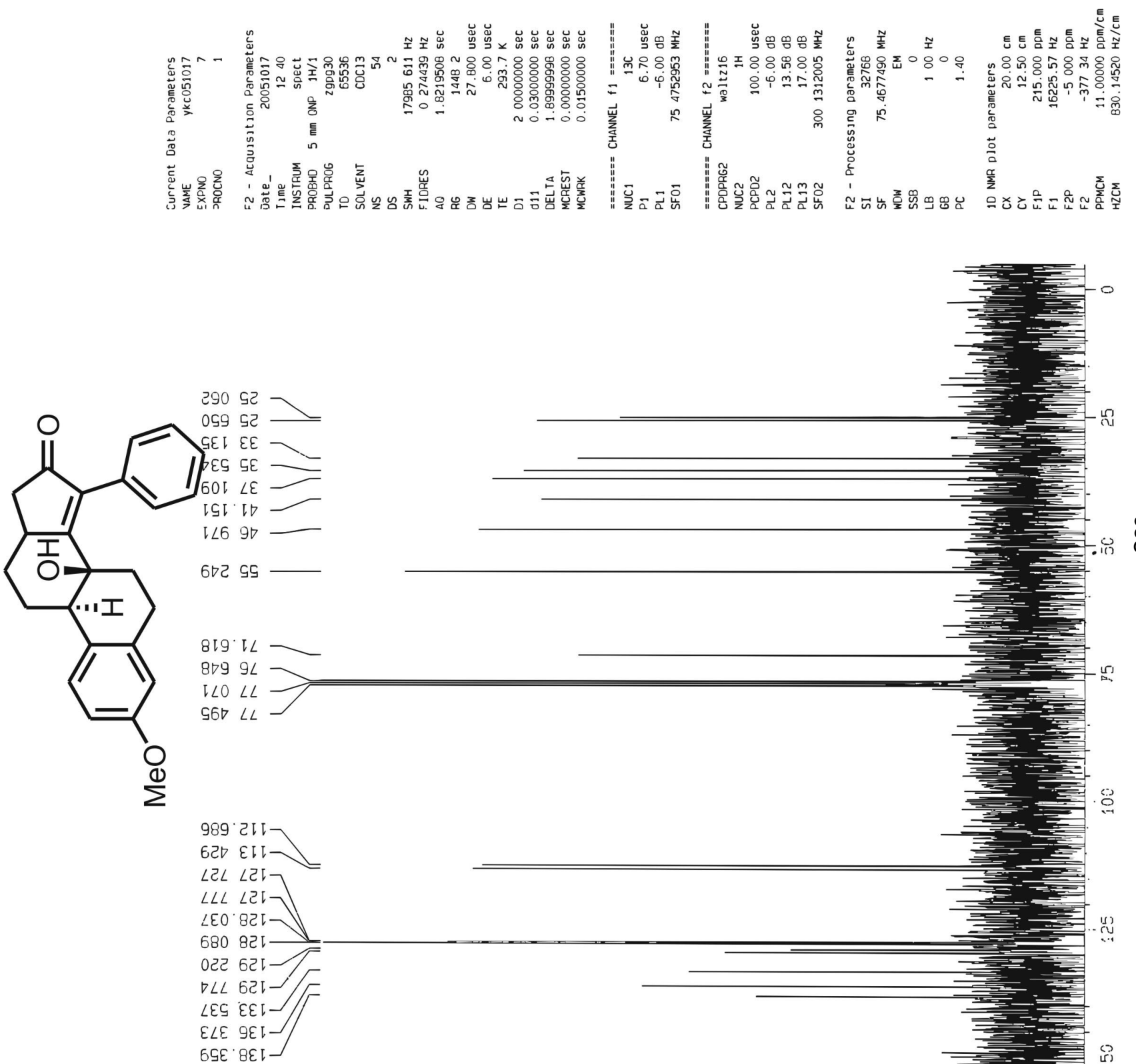

५ट0 8ธิ -

$\varepsilon 589\llcorner\square$

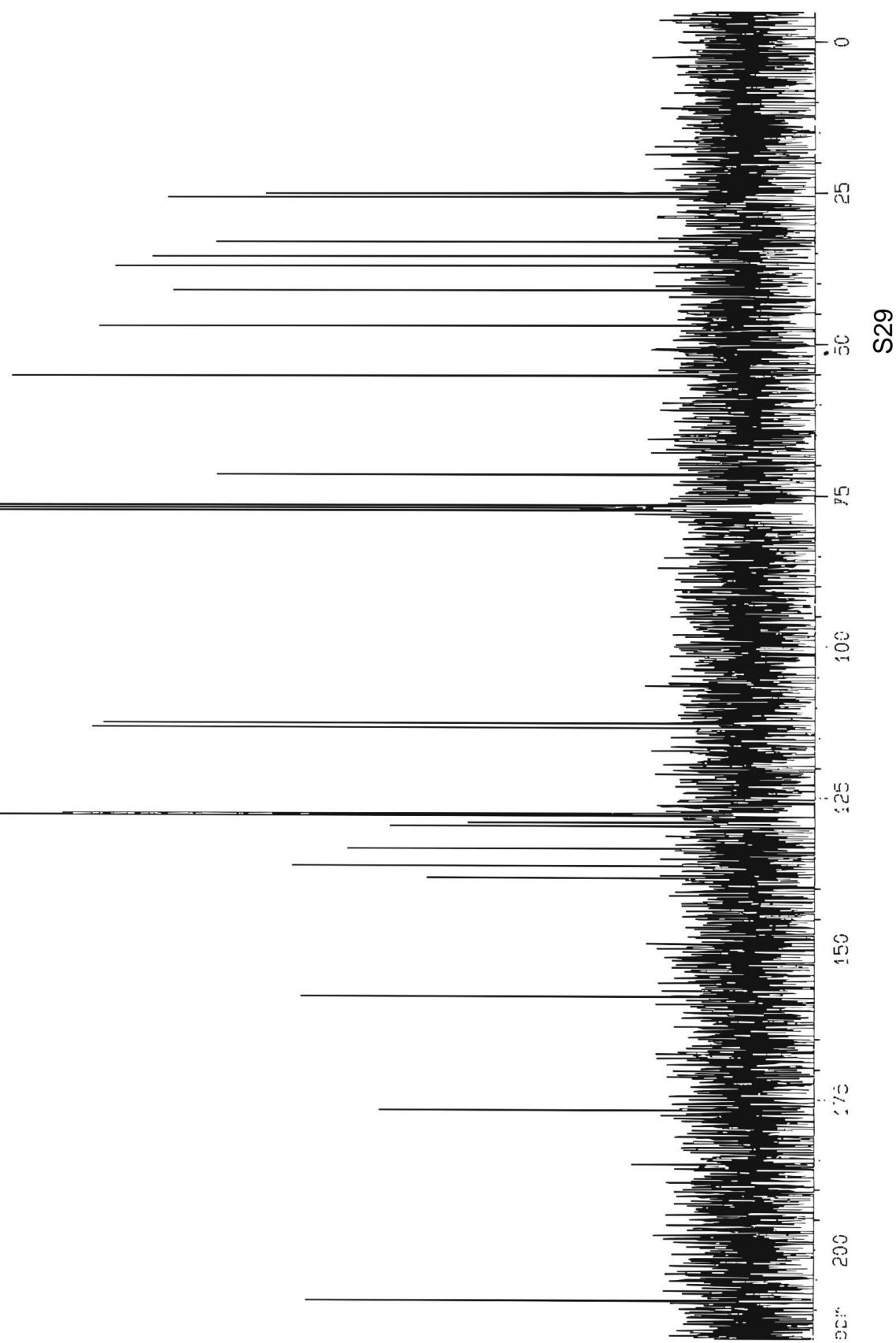




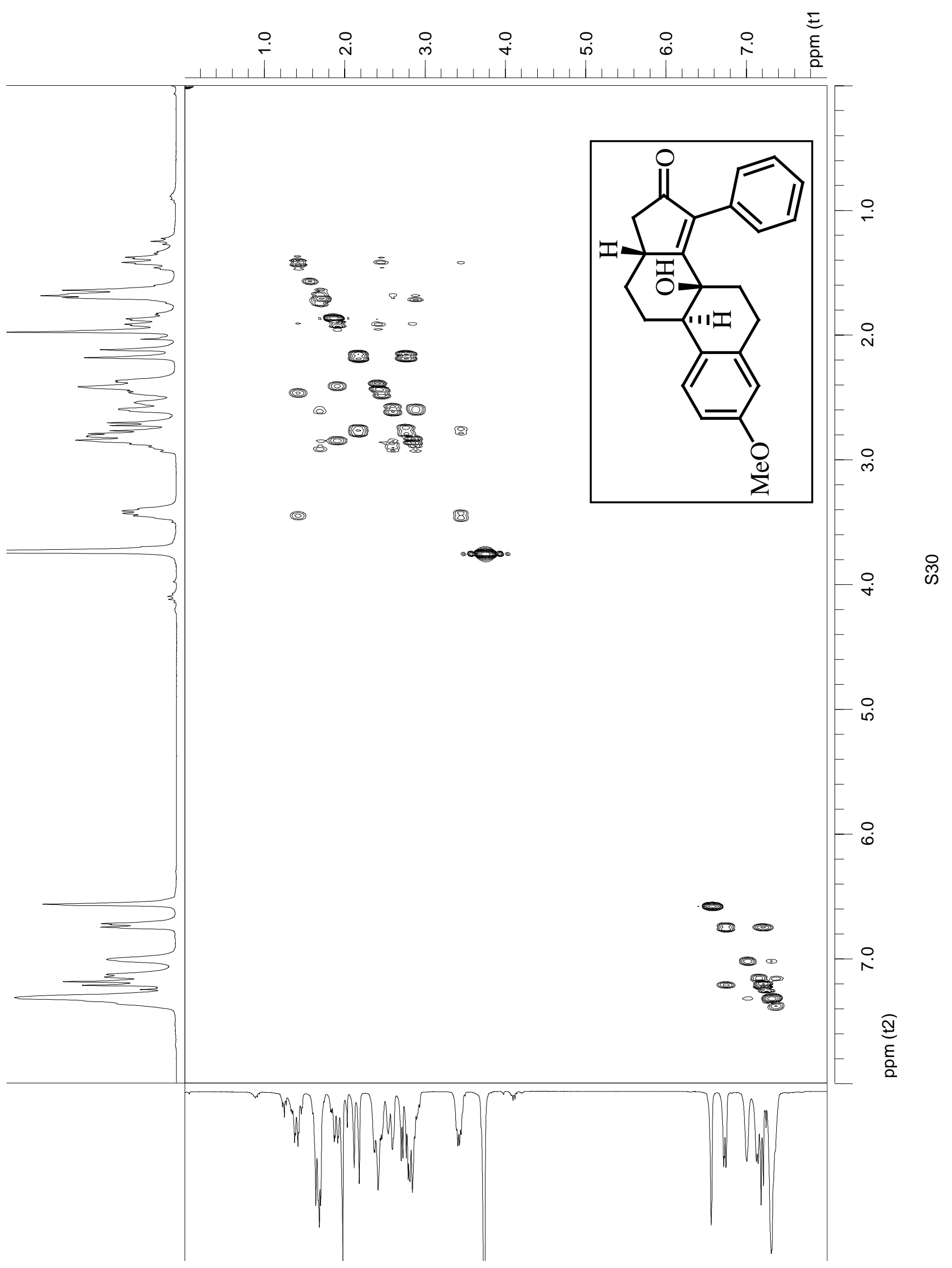




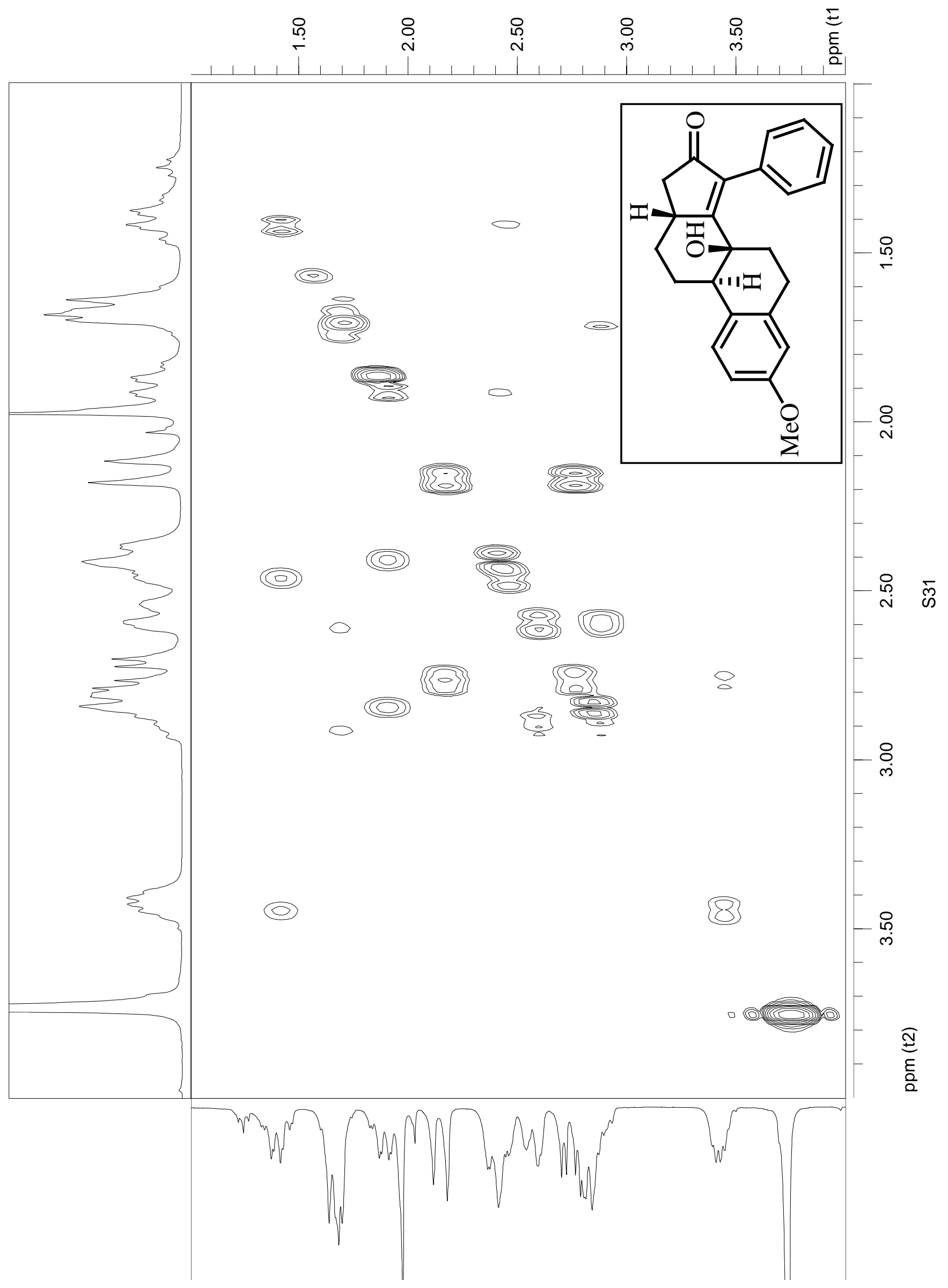



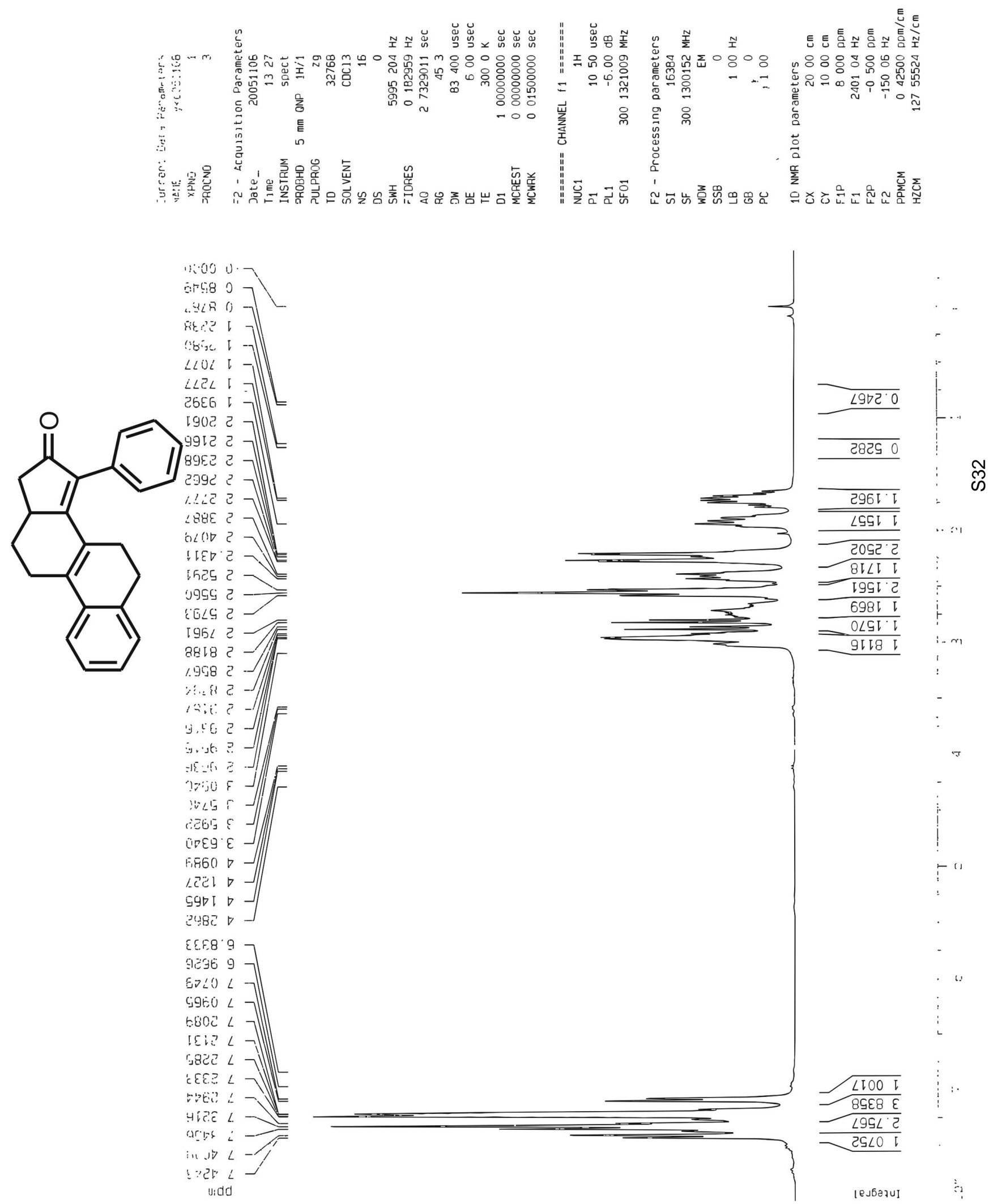

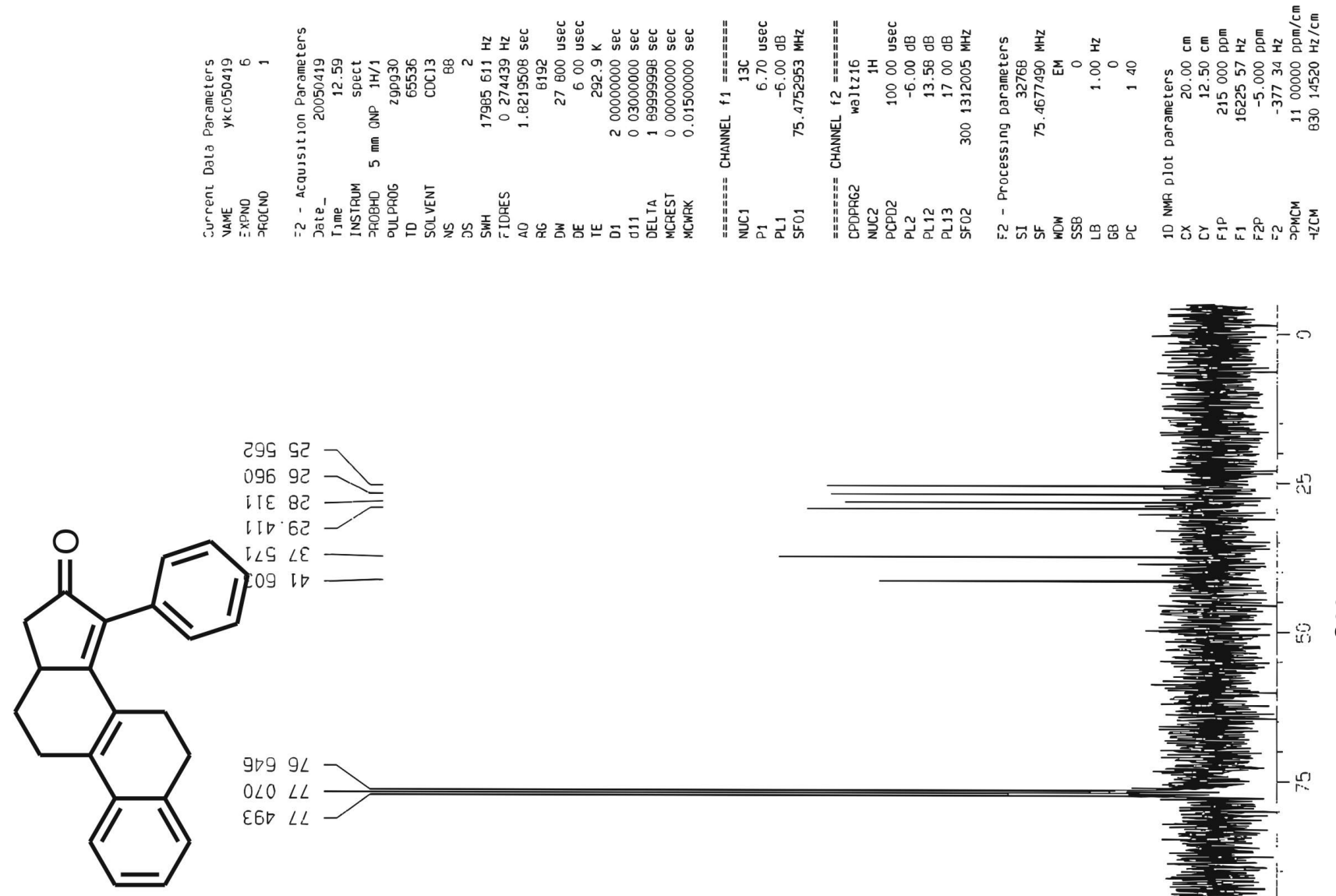

90996

$0 \angle 0 L$

ट99 9ट

09692

I 8 ह

IID. $65=$

IIV

I09 10

$\varepsilon \in \nabla L L$

ट0I म्टा

ट९9 9टा

8ट० $\angle 2 \downarrow$

$\varepsilon 69$ ८टा

$916 \angle 21$

II 82 I

689621

9C8 Є己टI

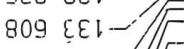

gI8 $D E I-$

6I6 ธEโ-

$\nabla \nabla G \angle E I-$

$\varepsilon \angle E$ Oワ

LVS $89 ז$

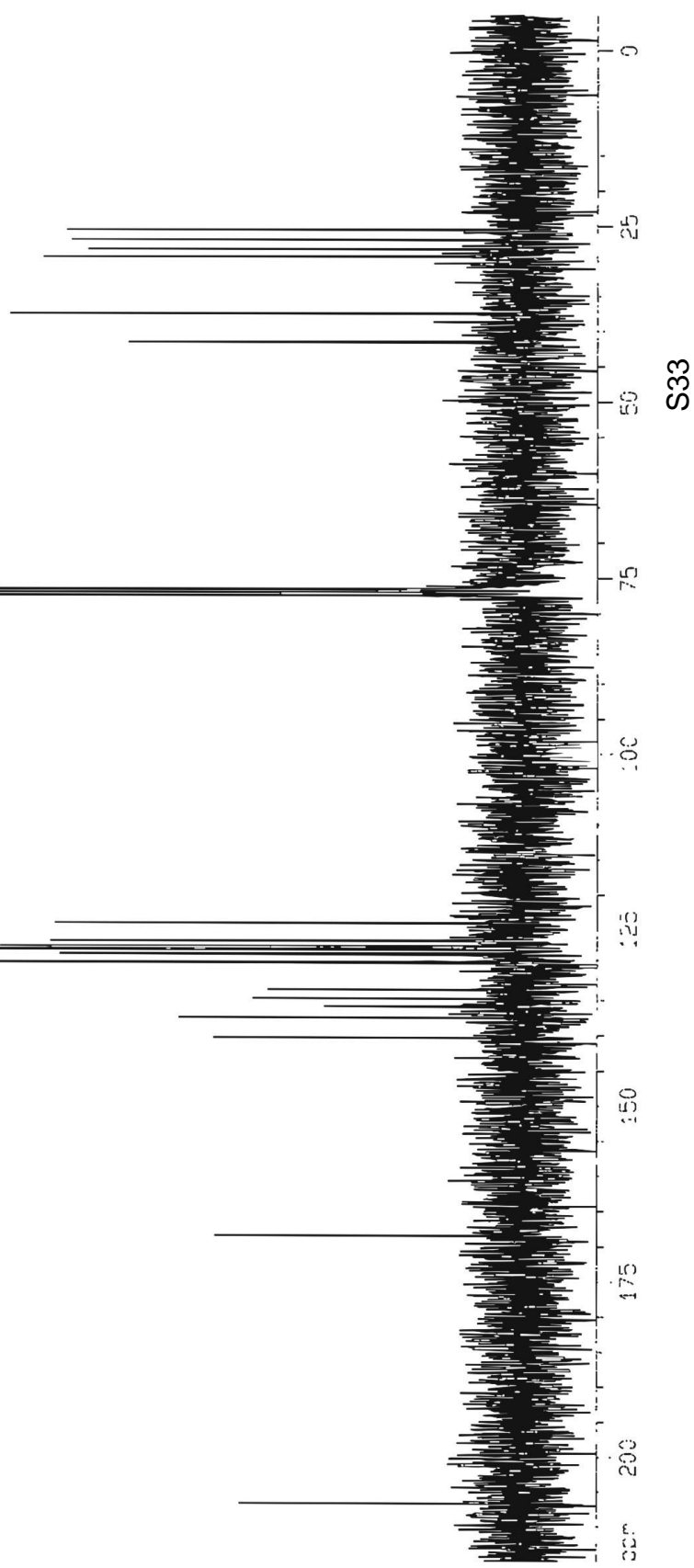



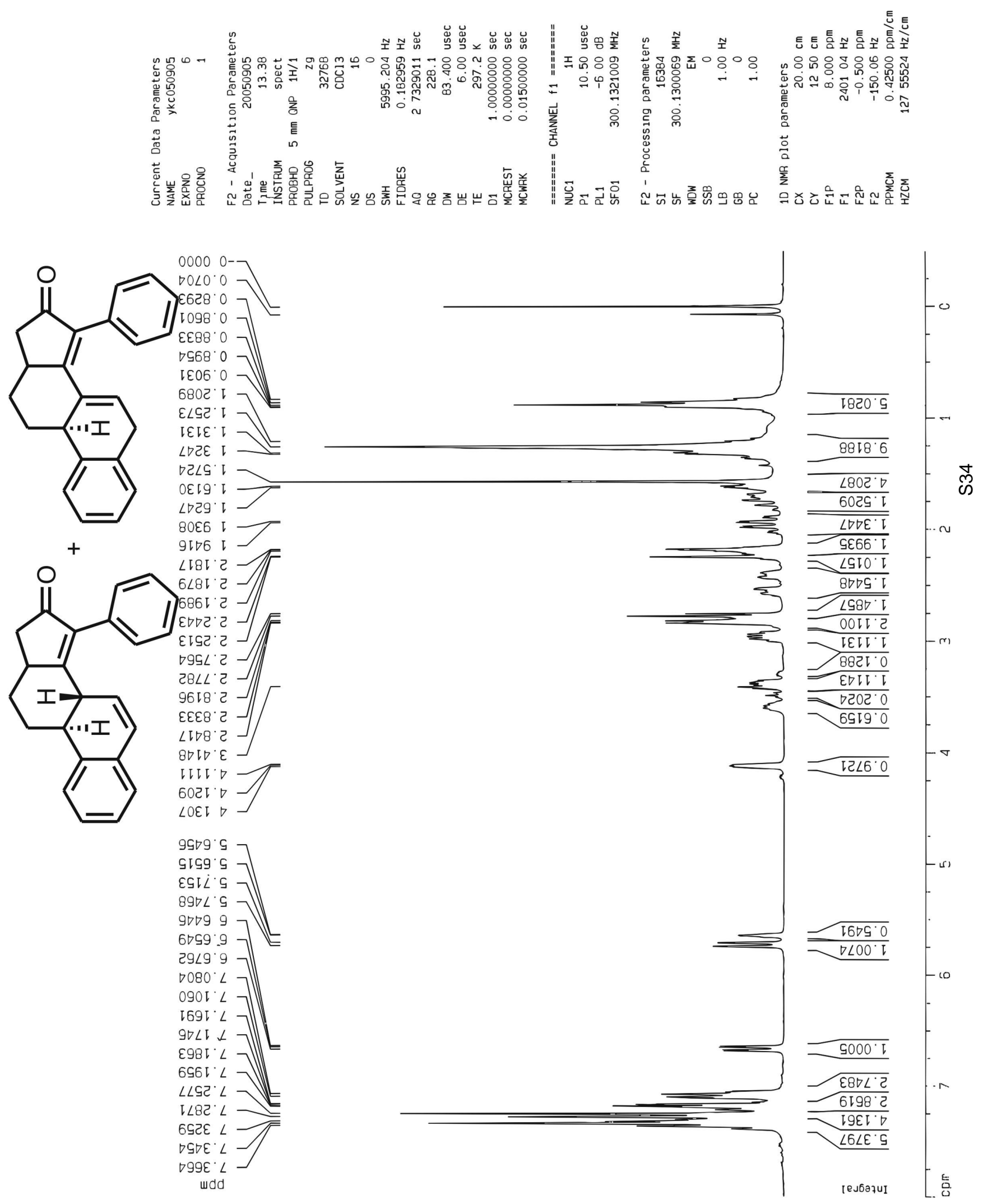

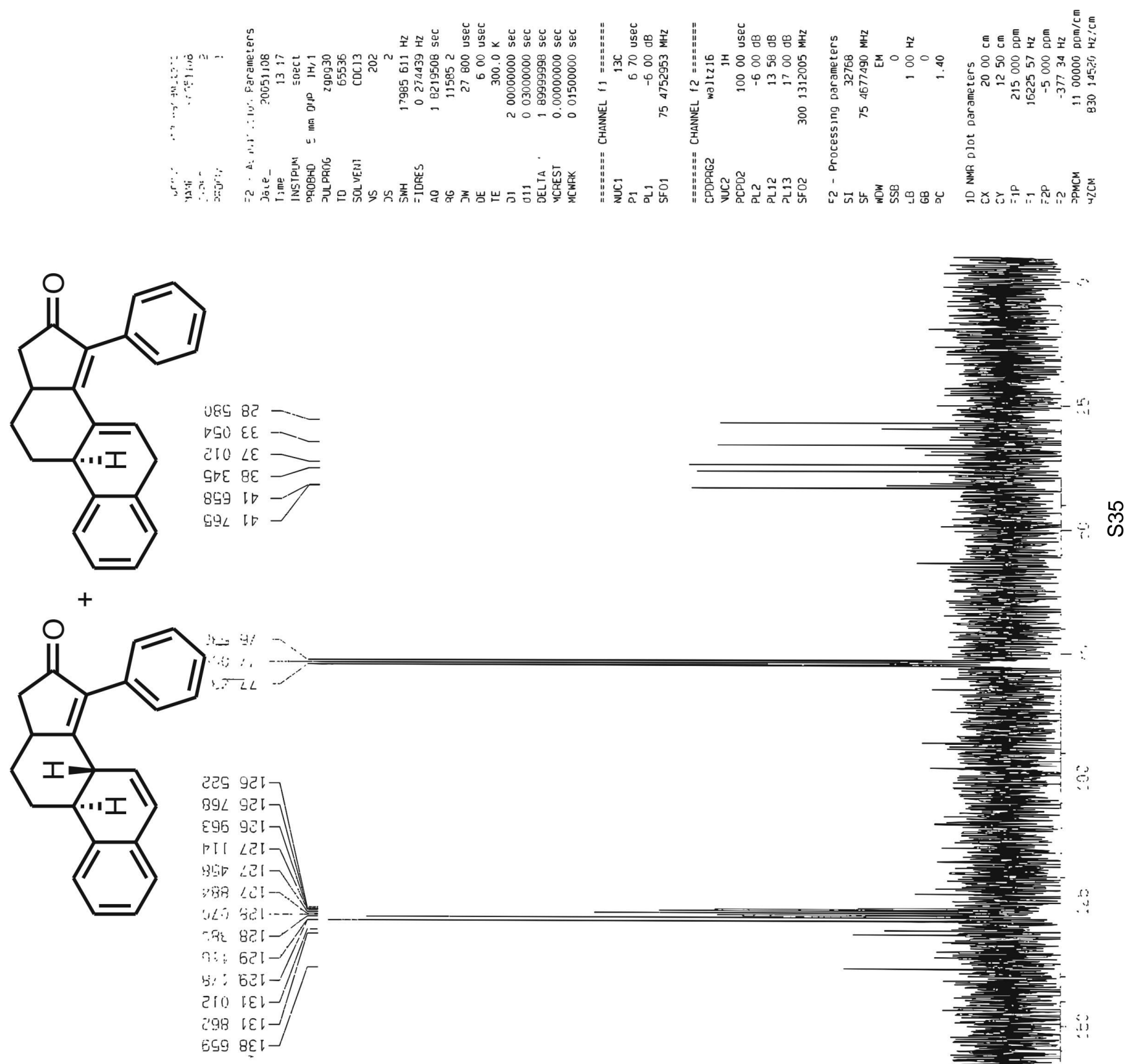

$\because 1 . \quad 21 .-\cdots$ 


\section{(III) X-ray Crystal Structural Data of 4a}

Single crystal suitable for $\mathrm{x}$-ray analysis of $\mathbf{4 a}$ was grown by slow diffusion of diethyl ether to dichloromethane solution of $\mathbf{4 a}$ in a freezer (at $-15{ }^{\circ} \mathrm{C}$ ). X-ray data for single crystal was collected on an Enraf-Nonius CCD single crystal X-ray diffractometer at room temperature using graphite-monochromated MoK $\alpha$ radiation $(\lambda$ $=0.71073 \AA$ ). The structure was solved by direct methods (SHELXS-97), and refined against all $\mathrm{F}^{2}$ data (SHELXS-97). All non-hydrogen atoms were refined with anisotropic thermal parameters and the hydrogen atoms were treated as idealized contributions.

Table 1. Crystal data and structure refinement for $\mathbf{4 a}$.

\begin{tabular}{ll}
\hline Empirical formula & $\mathrm{C}_{23} \mathrm{H}_{22} \mathrm{O}_{2}$ \\
\hline Formula weight & 330.41 \\
\hline Temperature & $293(2) \mathrm{K}$ \\
\hline Wavelength & $0.71073 \square$ \\
\hline Crystal system, space group & Orthorhombic, Pc21b \\
\hline Unit cell dimensions & $\mathrm{a}=8.5096(5) \square \quad \alpha=90 \mathrm{deg}$ \\
\cline { 2 - 2 } & $\mathrm{b}=9.1160(3) \square \quad \beta=90 \mathrm{deg}$ \\
\cline { 2 - 2 } & $\mathrm{c}=22.3675(12) \square \quad \gamma=90 \mathrm{deg}$ \\
\hline Volume & $1735.13(15) \square$ \\
\hline Z, Calculated density & $4, \quad 1.265 \mathrm{Mg} / \mathrm{m}^{3}$ \\
\hline Absorption coefficient & $0.079 \mathrm{~mm}^{-1}$ \\
\hline F(000) & 704 \\
\hline Crystal size & $0.13 \square 0.13 \quad \square 0.15 \mathrm{~mm}$ \\
\hline$\theta$ range for data collection & 3.40 to $27.53 \mathrm{deg}$ \\
\hline Limiting indices & $-10 \leq \mathrm{h} \leq 11,-8 \leq \mathrm{k} \leq 11,-28 \leq \mathrm{l} \leq 29$ \\
\hline Reflections collected / unique & $5985 / 3498[\mathrm{R}(\mathrm{int})=0.0460]$ \\
\hline Completeness to theta $=27.53$ & $98.7 \%$ \\
\hline Refinement method & Full-matrix least-squares on $\mathrm{F}^{2}$ \\
\hline Data / restraints / parameters & $3498 / 1 / 230$ \\
\hline Goodness-of-fit on $\mathrm{F}^{2}$ & 1.047 \\
\hline Final R indices [I $>2$ sigma(I)] & $\mathrm{R} 1=0.0491, \mathrm{wR} 2=0.1036$ \\
\hline R indices (all data) & $\mathrm{R} 1=0.0757, \mathrm{wR} 2=0.1156$ \\
\hline Largest diff. peak and hole & 0.141 and -0.163 e. $\AA^{-3}$ \\
\hline
\end{tabular}


Table 2. Atomic coordinates $\left(\square 10^{4}\right)$ and equivalent isotropic displacement parameters $\left(\square^{2} \square 10^{3}\right)$ for $\mathbf{4 a}$. U(eq) is defined as one third of the trace of the orthogonalized Uij tensor.

\begin{tabular}{ccccc} 
& $\mathrm{x}$ & $\mathrm{y}$ & $\mathrm{z}$ & $\mathrm{U}(\mathrm{eq})$ \\
\hline $\mathrm{O}(1)$ & $5359(1)$ & $7038(3)$ & $1131(3)$ & $56(1)$ \\
$\mathrm{O}(2)$ & $3597(1)$ & $4698(2)$ & $4789(2)$ & $41(1)$ \\
$\mathrm{C}(1)$ & $1978(1)$ & $3365(4)$ & $2983(4)$ & $52(1)$ \\
$\mathrm{C}(2)$ & $1568(2)$ & $2292(5)$ & $3518(4)$ & $58(1)$ \\
$\mathrm{C}(3)$ & $1751(2)$ & $1018(5)$ & $4312(4)$ & $62(1)$ \\
$\mathrm{C}(4)$ & $2357(2)$ & $785(4)$ & $4518(4)$ & $57(1)$ \\
$\mathrm{C}(5)$ & $2776(1)$ & $1826(4)$ & $3970(3)$ & $42(1)$ \\
$\mathrm{C}(6)$ & $3428(1)$ & $1487(4)$ & $4223(4)$ & $44(1)$ \\
$\mathrm{C}(7)$ & $3840(1)$ & $2460(3)$ & $3246(3)$ & $40(1)$ \\
$\mathrm{C}(8)$ & $3653(1)$ & $4186(3)$ & $3288(3)$ & $33(1)$ \\
$\mathrm{C}(9)$ & $3032(1)$ & $4341(3)$ & $2573(3)$ & $38(1)$ \\
$\mathrm{C}(10)$ & $2589(1)$ & $3162(3)$ & $3210(3)$ & $40(1)$ \\
$\mathrm{C}(11)$ & $2809(1)$ & $6049(4)$ & $2623(4)$ & $53(1)$ \\
$\mathrm{C}(12)$ & $3247(1)$ & $7163(4)$ & $1878(4)$ & $53(1)$ \\
$\mathrm{C}(13)$ & $3866(1)$ & $7030(3)$ & $2564(4)$ & $41(1)$ \\
$\mathrm{C}(14)$ & $4076(1)$ & $5335(3)$ & $2576(3)$ & $34(1)$ \\
$\mathrm{C}(15)$ & $4632(1)$ & $5187(3)$ & $2021(3)$ & $37(1)$ \\
$\mathrm{C}(16)$ & $4857(1)$ & $6755(3)$ & $1581(3)$ & $42(1)$ \\
$\mathrm{C}(17)$ & $4365(1)$ & $7933(3)$ & $1784(4)$ & $47(1)$ \\
$\mathrm{C}(18)$ & $5037(1)$ & $3800(3)$ & $1873(3)$ & $40(1)$ \\
$\mathrm{C}(19)$ & $4934(2)$ & $2608(4)$ & $882(4)$ & $55(1)$ \\
$\mathrm{C}(20)$ & $5329(2)$ & $1321(4)$ & $805(4)$ & $70(1)$ \\
$\mathrm{C}(21)$ & $5824(2)$ & $1293(5)$ & $1713(5)$ & $78(1)$ \\
$\mathrm{C}(22)$ & $5941(2)$ & $2500(5)$ & $2637(5)$ & $69(1)$ \\
$\mathrm{C}(23)$ & $5549(1)$ & $3738(4)$ & $2731(4)$ & $53(1)$
\end{tabular}


Table 3. Bond lengths [ $\square]$ and angles [deg] for $\mathbf{4 a}$.

\begin{tabular}{|c|c|c|c|}
\hline $\mathrm{O}(1)-\mathrm{C}(16)$ & $1.220(3)$ & $C(5)-C(6)-C(7)$ & $113.1(2)$ \\
\hline $\mathrm{O}(2)-\mathrm{C}(8)$ & $1.442(3)$ & $\mathrm{C}(6)-\mathrm{C}(7)-\mathrm{C}(8)$ & $110.0(2)$ \\
\hline $\mathrm{C}(1)-\mathrm{C}(2)$ & $1.384(5)$ & $\mathrm{O}(2)-\mathrm{C}(8)-\mathrm{C}(14)$ & $105.5(2)$ \\
\hline $\mathrm{C}(1)-\mathrm{C}(10)$ & $1.392(4)$ & $\mathrm{O}(2)-\mathrm{C}(8)-\mathrm{C}(7)$ & $109.8(2)$ \\
\hline $\mathrm{C}(2)-\mathrm{C}(3)$ & $1.366(5)$ & $\mathrm{C}(14)-\mathrm{C}(8)-\mathrm{C}(7)$ & $116.2(2)$ \\
\hline$C(3)-C(4)$ & $1.383(5)$ & $\mathrm{O}(2)-\mathrm{C}(8)-\mathrm{C}(9)$ & $107.3(2)$ \\
\hline $\mathrm{C}(4)-\mathrm{C}(5)$ & $1.382(4)$ & $\mathrm{C}(14)-\mathrm{C}(8)-\mathrm{C}(9)$ & $109.2(2)$ \\
\hline$C(5)-C(10)$ & $1.395(4)$ & $\mathrm{C}(7)-\mathrm{C}(8)-\mathrm{C}(9)$ & $108.6(2)$ \\
\hline $\mathrm{C}(5)-\mathrm{C}(6)$ & $1.505(4)$ & $C(10)-C(9)-C(11)$ & $113.6(2)$ \\
\hline$C(6)-C(7)$ & $1.527(4)$ & $\mathrm{C}(10)-\mathrm{C}(9)-\mathrm{C}(8)$ & $111.6(2)$ \\
\hline $\mathrm{C}(7)-\mathrm{C}(8)$ & $1.527(4)$ & $\mathrm{C}(11)-\mathrm{C}(9)-\mathrm{C}(8)$ & $111.2(2)$ \\
\hline$C(8)-C(14)$ & $1.508(4)$ & $C(1)-C(10)-C(5)$ & $117.9(3)$ \\
\hline $\mathrm{C}(8)-\mathrm{C}(9)$ & $1.540(4)$ & $C(1)-C(10)-C(9)$ & $119.9(3)$ \\
\hline$C(9)-C(10)$ & $1.524(4)$ & $\mathrm{C}(5)-\mathrm{C}(10)-\mathrm{C}(9)$ & $122.1(2)$ \\
\hline $\mathrm{C}(9)-\mathrm{C}(11)$ & $1.537(4)$ & $\mathrm{C}(12)-\mathrm{C}(11)-\mathrm{C}(9)$ & $111.5(2)$ \\
\hline$C(11)-C(12)$ & $1.523(4)$ & $C(11)-C(12)-C(13)$ & $110.8(3)$ \\
\hline $\mathrm{C}(12)-\mathrm{C}(13)$ & $1.524(4)$ & $C(14)-C(13)-C(12)$ & $110.8(2)$ \\
\hline$C(13)-C(14)$ & $1.516(4)$ & $\mathrm{C}(14)-\mathrm{C}(13)-\mathrm{C}(17)$ & $104.8(2)$ \\
\hline$C(13)-C(17)$ & $1.531(4)$ & $\mathrm{C}(12)-\mathrm{C}(13)-\mathrm{C}(17)$ & $115.8(3)$ \\
\hline$C(14)-C(15)$ & $1.350(4)$ & $\mathrm{C}(15)-\mathrm{C}(14)-\mathrm{C}(8)$ & $132.8(2)$ \\
\hline$C(15)-C(16)$ & $1.481(4)$ & $C(15)-C(14)-C(13)$ & $111.8(2)$ \\
\hline$C(15)-C(18)$ & $1.494(4)$ & $\mathrm{C}(8)-\mathrm{C}(14)-\mathrm{C}(13)$ & $115.2(2)$ \\
\hline$C(16)-C(17)$ & $1.500(4)$ & $\mathrm{C}(14)-\mathrm{C}(15)-\mathrm{C}(16)$ & $109.3(2)$ \\
\hline $\mathrm{C}(18)-\mathrm{C}(19)$ & $1.378(5)$ & $\mathrm{C}(14)-\mathrm{C}(15)-\mathrm{C}(18)$ & $131.8(3)$ \\
\hline $\mathrm{C}(18)-\mathrm{C}(23)$ & $1.387(4)$ & $C(16)-C(15)-C(18)$ & $118.8(2)$ \\
\hline$C(19)-C(20)$ & $1.408(5)$ & $\mathrm{O}(1)-\mathrm{C}(16)-\mathrm{C}(15)$ & $125.5(3)$ \\
\hline$C(20)-C(21)$ & $1.382(6)$ & $\mathrm{O}(1)-\mathrm{C}(16)-\mathrm{C}(17)$ & $125.8(3)$ \\
\hline$C(21)-C(22)$ & $1.354(7)$ & $C(15)-C(16)-C(17)$ & $108.7(2)$ \\
\hline \multirow[t]{2}{*}{$C(22)-C(23)$} & $1.373(5)$ & $C(16)-C(17)-C(13)$ & $104.9(2)$ \\
\hline & & $C(19)-C(18)-C(23)$ & $118.7(3)$ \\
\hline $\mathrm{C}(2)-\mathrm{C}(1)-\mathrm{C}(10)$ & $121.1(3)$ & $\mathrm{C}(19)-\mathrm{C}(18)-\mathrm{C}(15)$ & $122.7(3)$ \\
\hline $\mathrm{C}(3)-\mathrm{C}(2)-\mathrm{C}(1)$ & $120.7(3)$ & $C(23)-C(18)-C(15)$ & $118.7(3)$ \\
\hline $\mathrm{C}(2)-\mathrm{C}(3)-\mathrm{C}(4)$ & $118.7(3)$ & $C(18)-C(19)-C(20)$ & $120.0(3)$ \\
\hline $\mathrm{C}(5)-\mathrm{C}(4)-\mathrm{C}(3)$ & $121.5(3)$ & $C(21)-C(20)-C(19)$ & $119.0(4)$ \\
\hline$C(4)-C(5)-C(10)$ & $119.9(3)$ & $C(22)-C(21)-C(20)$ & $121.0(4)$ \\
\hline$C(4)-C(5)-C(6)$ & $118.5(3)$ & $\mathrm{C}(21)-\mathrm{C}(22)-\mathrm{C}(23)$ & $119.9(4)$ \\
\hline$C(10)-C(5)-C(6)$ & $121.5(2)$ & $\mathrm{C}(22)-\mathrm{C}(23)-\mathrm{C}(18)$ & $121.4(4)$ \\
\hline
\end{tabular}


Table 4. Anisotropic displacement parameters $\left(\square^{2} \square 10^{3}\right)$ for $\mathbf{4 a}$.

The anisotropic displacement factor exponent takes the form: $-2 \pi^{2}\left[h^{2} a^{2} \square U 11+\ldots+\right.$ $2 \mathrm{~h} \mathrm{k} \mathrm{a} \square \mathrm{b} \square \mathrm{U} 12]$

\begin{tabular}{ccccccc} 
& $\mathrm{U} 11$ & $\mathrm{U} 22$ & $\mathrm{U} 33$ & $\mathrm{U} 23$ & $\mathrm{U} 13$ & $\mathrm{U} 12$ \\
\hline $\mathrm{O}(1)$ & $43(1)$ & $51(1)$ & $74(2)$ & $8(1)$ & $15(1)$ & $-5(1)$ \\
$\mathrm{O}(2)$ & $44(1)$ & $43(1)$ & $37(1)$ & $-1(1)$ & $3(1)$ & $-2(1)$ \\
$\mathrm{C}(1)$ & $40(2)$ & $69(2)$ & $49(2)$ & $4(2)$ & $-7(1)$ & $-7(2)$ \\
$\mathrm{C}(2)$ & $38(2)$ & $79(3)$ & $56(2)$ & $-1(2)$ & $0(1)$ & $-14(2)$ \\
$\mathrm{C}(3)$ & $56(2)$ & $68(3)$ & $63(2)$ & $0(2)$ & $8(2)$ & $-27(2)$ \\
$\mathrm{C}(4)$ & $58(2)$ & $52(2)$ & $61(2)$ & $5(2)$ & $3(2)$ & $-17(2)$ \\
$\mathrm{C}(5)$ & $44(2)$ & $42(2)$ & $41(2)$ & $0(1)$ & $2(1)$ & $-8(1)$ \\
$\mathrm{C}(6)$ & $46(2)$ & $36(2)$ & $51(2)$ & $7(1)$ & $-1(1)$ & $-2(1)$ \\
$\mathrm{C}(7)$ & $38(1)$ & $35(2)$ & $46(2)$ & $1(1)$ & $-1(1)$ & $-1(1)$ \\
$\mathrm{C}(8)$ & $33(1)$ & $33(1)$ & $34(1)$ & $3(1)$ & $-1(1)$ & $0(1)$ \\
$\mathrm{C}(9)$ & $33(1)$ & $43(2)$ & $38(1)$ & $8(1)$ & $-1(1)$ & $-2(1)$ \\
$\mathrm{C}(10)$ & $37(2)$ & $49(2)$ & $34(1)$ & $0(1)$ & $-1(1)$ & $-5(1)$ \\
$\mathrm{C}(11)$ & $34(1)$ & $52(2)$ & $73(2)$ & $19(2)$ & $1(2)$ & $5(1)$ \\
$\mathrm{C}(12)$ & $43(2)$ & $42(2)$ & $73(2)$ & $17(2)$ & $1(2)$ & $5(1)$ \\
$\mathrm{C}(13)$ & $38(1)$ & $34(2)$ & $51(2)$ & $6(1)$ & $7(1)$ & $3(1)$ \\
$\mathrm{C}(14)$ & $34(1)$ & $34(2)$ & $35(1)$ & $3(1)$ & $-3(1)$ & $0(1)$ \\
$\mathrm{C}(15)$ & $34(1)$ & $36(2)$ & $40(1)$ & $0(1)$ & $0(1)$ & $0(1)$ \\
$\mathrm{C}(16)$ & $40(2)$ & $39(2)$ & $47(2)$ & $1(1)$ & $3(1)$ & $-3(1)$ \\
$\mathrm{C}(17)$ & $46(2)$ & $36(2)$ & $59(2)$ & $10(2)$ & $7(2)$ & $-1(1)$ \\
$\mathrm{C}(18)$ & $40(2)$ & $36(2)$ & $44(2)$ & $6(1)$ & $10(1)$ & $2(1)$ \\
$\mathrm{C}(19)$ & $57(2)$ & $52(2)$ & $55(2)$ & $-5(2)$ & $14(2)$ & $-4(2)$ \\
$\mathrm{C}(20)$ & $102(3)$ & $42(2)$ & $66(2)$ & $-7(2)$ & $36(2)$ & $0(2)$ \\
$\mathrm{C}(21)$ & $92(3)$ & $72(3)$ & $69(3)$ & $17(2)$ & $25(2)$ & $43(2)$ \\
$\mathrm{C}(22)$ & $63(2)$ & $80(3)$ & $65(2)$ & $10(2)$ & $10(2)$ & $32(2)$ \\
$\mathrm{C}(23)$ & $46(2)$ & $60(2)$ & $54(2)$ & $2(2)$ & $6(2)$ & $13(2)$
\end{tabular}


Table 5. Hydrogen coordinates $\left(\square 10^{4}\right)$ and isotropic displacement parameters $\left(\square^{2} \square\right.$ $10^{3}$ ) for $\mathbf{4 a}$.

\begin{tabular}{rcccc} 
& $x$ & $y$ & $z$ & $U(e q)$ \\
\hline$H(1)$ & 1844 & 4237 & 2464 & 63 \\
$\mathrm{H}(2)$ & 1163 & 2440 & 3336 & 69 \\
$\mathrm{H}(3)$ & 1474 & 322 & 4706 & 74 \\
$\mathrm{H}(4)$ & 2486 & -93 & 5036 & 69 \\
$\mathrm{H}(6 \mathrm{~A})$ & 3502 & 380 & 4042 & 67 \\
$\mathrm{H}(6 \mathrm{~B})$ & 3523 & 1698 & 5242 & 67 \\
$\mathrm{H}(7 \mathrm{~A})$ & 3820 & 2074 & 2246 & 60 \\
$\mathrm{H}(7 \mathrm{~B})$ & 4250 & 2359 & 3584 & 60 \\
$\mathrm{H}(9)$ & 3081 & 4071 & 1535 & 57 \\
$\mathrm{H}(11 \mathrm{~A})$ & 2424 & 6117 & 2138 & 79 \\
$\mathrm{H}(11 \mathrm{~B})$ & 2756 & 6366 & 3637 & 79 \\
$\mathrm{H}(12 \mathrm{~A})$ & 3104 & 8235 & 1972 & 79 \\
$\mathrm{H}(12 \mathrm{~B})$ & 3270 & 6914 & 841 & 79 \\
$\mathrm{H}(13)$ & 3843 & 7401 & 3580 & 61 \\
$\mathrm{H}(17 \mathrm{~A})$ & 4229 & 8329 & 844 & 71 \\
$\mathrm{H}(17 \mathrm{~B})$ & 4500 & 8811 & 2377 & 71 \\
$\mathrm{H}(19)$ & 4604 & 2652 & 264 & 66 \\
$\mathrm{H}(20)$ & 5258 & 502 & 152 & 84 \\
$\mathrm{H}(21)$ & 6080 & 432 & 1690 & 93 \\
$\mathrm{H}(22)$ & 6286 & 2490 & 3206 & 83 \\
$\mathrm{H}(23)$ & 5629 & 4552 & 3383 & 64
\end{tabular}

